\title{
Accounting Recognition, Moral hazard, and Communication
}

\author{
Pierre Jinghong Liang \\ January 2000 \\ Graduate School of Industrial A dministration \\ Carnegie M ellon University \\ Tech and Frew Streets \\ Pittsburgh, PA 15213 \\ Email: liangj@andrew.cmu.edu
}

\begin{abstract}
Two complementary sources of information are studied in a multi-period agency model. One is an accounting source which partially but credibly conveys the agent's private information through accounting recognition. The other is an unverified communication by the agent (i.e., a self-report). In a simple setting with no communication, alternative labor market frictions lead to alternative optimal recognition policies. When the agent is allowed to communicate his private information, accounting signals serve as a veracity check on the agent's self-report. Finally, such communication sometimes makes delaying the recognition optimal. We see contracting and confirmatory roles of accounting as its comparative advantage. As a source of information, accounting is valuable because accounting reports are credible, comprehensive, and subject to careful and professional judgment. While other information sources may be more timely in providing valuation information about an entity, audited accounting information, when used in explicit or implicit contracts, ensures the accuracy of the reports from non-accounting sources.
\end{abstract}

Suggestions from my dissertation committee chairman Professor Joel Demski and committee members Professor David Sappington, Professor Bipin Ajinkya, and Professor Karl Hackenbrack are gratefully acknowledged. Comments from A nwer A hmed, Rick Antle, Sanjeev Bhojraj, Henry Cao, Hans Frimor, Jon Glover, Russ L undholm, an anonymous referee, participants at 1999 Contemporary Accounting Research Conference and workshops at Columbia U niversity, Carnegie M ellon U niversity, U niversity of Florida, and U niversity of Texas at Dallas are appreciated. Financial support is partially provided by the A ndersen Foundation Doctoral Dissertation Fellowship program. 


\section{Accounting Recognition, M oral Hazard, and Communication}

\section{Section I Introduction}

All information systems manage their sources. The U.S. L abor D epartment uses elaborate rules and procedures to determine whether the price of a particular consumer good should be included in calculating the consumer price index (CPI). Judges use legal codes and their professional opinions to decide whether a piece of evidence should be heard by a jury. Likewise, accountants are selective about what can be recorded in an entity's financial records. The primary means to achieve this selectivity in accounting is through recognition rules, which dictate how and at what point in time economic events may enter accounting books. For example, according to GAAP, internally generated goodwill and some types of holding gains are not recognized in the accounting records until the corresponding assets are sold.

In the accounting policy arena, rhetoric about recognition is abundant. In its conceptual framework, the FASB prescribes four fundamental recognition criteria: definition, measurability, relevance, and reliability. ${ }^{1}$ The conceptual statements further emphasize the tension between relevance and reliability. For instance, recording revenue before cash is received may sacrifice some information reliability. However, if "enough" uncertainty has been resolved, recognition is justified because relevant information may be conveyed in time to help users make various decisions.

The objective of this paper is to examine the economic forces that underlie the accounting recognition issue in order to better understand the comparative advantages of accounting as a source of information. N umerous studies have addressed the recognition issue. In the first half of $20^{\text {th }}$ century, accounting writers stressed an economic measurement perspective (e.g., Paton [1922], Canning [1929],

1 FASB Statement of Financial A ccounting Concepts N o. 5, Recognition and M easurement in Financial Statements of Business Enterprises, paragraph 63. Essentially, accounting recognition may occur when the economic item in question has met the definition of an accounting element and is measurable, relevant, and reliable. All four criteria are subject to the pervasive cost-benefit constraint and a materiality threshold. 
and A lexander [1948]). The recognition debate was part of the larger income debate. ${ }^{2}$ Contemporary authors have adopted an information content approach (e. g., B eaver [1968], Butterworth [1972], Demski [1972], and F eltham [1972]). They view accounting as a source of information as opposed to a measure of some underlying stock or flow of value. Under this approach, recognition has been studied in the terms of consumption planning (e.g., Antle and Demski [1989]) and security price behavior (e.g., Antle, Demski, and Ryan [1994] and Beaver and Ryan [1995]).

In this paper, we add two themes to the recognition debate. First, we focus on the incentive use of accounting information (e.g., to evaluate and compensate managers). Prior research has stressed the valuation use (e.g., to predict the future payoff of an entity). However, accounting measures are widely used in managerial evaluation and compensation schemes (e. g., A ntle and Smith [1985], Lambert and Larcker [1987], and Sloan [1993]). In general, the information system best suited for valuation purposes may not be best suited for incentive (or stewardship) purposes (e.g., Gjesdal [1981] and Feltham and Xie [1994]). By implication, one would expect that the best recognition rule for valuation purposes may not be the best rule for stewardship purposes.

Second, we consider the interaction between accounting and non-accounting information sources. There are many non-accounting information sources concerning a typical corporate entity, such as voluntary disclosures by its managers and news stories from the financial press. Casual observation suggests information from these non-accounting sources is often more timely than the typical accounting source. When determining the optimal recognition rule, it is critical to consider other information users may al ready have.

We construct a multi-period agency setting in which the principal's major concern is motivating a privately informed agent. A Iternative recognition rules partially convey the agent's private information at

2 See AAA Committee Report [1965], Horngren [1965], and Sprouse [1965]. The broader accounting vs. economic income debate is illustrated by Paton [1922], Canning [1929], Edwards and Bell [1961], and Lee [1974]. 
different points in time. We then analyze the usefulness of these recognition rules. N ext, a manager's self-report is introduced, playing the role of a non-accounting information source. We use this expanded setting to study how other information sources affect the use of accounting information and the choice of the optimal recognition rule.

By adopting an agency perspective, this paper adds new insights to the recognition debate. First, we provide a setting where it is best to have recognition occur in the period when the moral hazard problem is most critical rather than the period when the most uncertain event in the earning process takes place. ${ }^{3}$ Second, and more importantly, we show that when other, less credible, information sources are present, the credibility of accounting information leads to a veracity check role. Specifically, contracting on audited accounting information helps encourage a truthful self-report by the manager. While the selfreport is, in equilibrium, useful in predicting future cash flows, we show it is the pending accounting signal that ensures the self-report is reliable. ${ }^{4}$ W hile feeding timely information to the security market is not the comparative advantage of accounting, the veracity check role makes accounting uniquely valuable among competing information sources. ${ }^{5}$ Third, the existence of an earlier self-report, coupled with this veracity check role of accounting, suggests that delaying accounting recognition may be optimal at times. Timeliness (early production and dissemination of information) is not necessarily a virtue for accounting

3 Antle and Demski [1989] considered a model of revenue recognition with moral hazard. However, in their setting, moral hazard exists only in one period (i.e., the first period). This interaction between severity of moral hazard and timing of recognition is, therefore, absent.

4 There have been a number of prior studies of agency models with communication. However, the emphasis has been placed upon (1) conditions under which communication is strictly valuable (e.g., Christensen [1981], Penno [1984]); (2) the trade-off between centralization and delegation of planning decisions (e. g., M elumad and Reichelstein [1987]); (3) the interaction between communication and the agent's different types of activities (e.g., directly related vs. indirectly related activities in Penno [1990a]); and (4) the function of internal audit (e.g., Penno [1990b]. In this paper, the focus is the explicit accounting structure (e.g., the timing of accounting recognition) in a multi-period agency setting.

5 Sundem, Dukes, and Elliott [1997] make a similar point in their monograph on the value of accounting and auditing. A uditing plays a very important role here. To be able to serve as a veracity check on other sources of information, the integrity of accounting information must be sustained. 
as a source of information. D elaying an accounting report can enhance its disciplining role (through the auditing process).

Section II describes the sequence of productive activities in the basic agency model. In Section III, we expand the basic model by introducing accounting signals as additional contracting variables. Section IV further expands the model by allowing a self-report by the agent and examines the veracity check issue. Section $\mathrm{V}$ gives concluding comments.

\section{Section II Organizational Setting}

A stochastic technology is operated by a manager (the agent) who is hired by the owner (the principal) of the technology. This agency relationship lasts for three periods. The agent supplies two unobservable labor inputs, denoted $a_{t} 0 \mathrm{~A}(t=1,2)$, at a pecuniary personal cost of $c\left(a_{t}\right){ }^{6}$ To use the simplest model to convey our main ideas, we employ binary structures wherever possible. Each labor input can be either high or low: $A=\{H, L\}$ with $c(H)>c(L)$, and $c(L)$ set to 0 . A fter supplying the labor input in period $t$, the agent privately observes a signal, denoted $z_{t} 0 z(t=1,2)$. Each signal can be either good or bad news: $Z=\{G, B\}$. A single output, denoted $x O X$, is realized and observed publicly at the end of the third period. The output can be zero or one: $X=\{0,1\}$. The monetary value of output $x$ is given by $q A$ with $q>0$. The principal pays $I_{t}$ to the agent at the end of period $t$ based upon the publicly available information at that time. Figure 1 summarizes the sequence of events.

We neutralize the principal's risk-sharing desire and consumption timing by assuming that the principal is risk-neutral and only cares about the end-of-the-game net cash flow. The principal's utility is given by $q A ! I_{1} ! I_{2} ! I_{3}$.

6 In the third period, there is no explicit productive input provided by the agent. The model yields the same results if an unobservable and productive $a_{3}$ is admitted. Sidestepping an explicit $a_{3}$ merely simplifies the calculation. 
The agent is risk-averse, with the utility function $U\left(I_{1}, I_{2}, I_{3} ; a_{1}, a_{2}\right)=! \exp \left(! r\left(I_{1}+I_{2}+I_{3}\right.\right.$ ! $\left.\left.c\left(a_{1}\right) ! c\left(a_{2}\right)\right)\right)$. The utility function exhibits constant absolute risk aversion (CARA) with the A rrow-Pratt measure $r(>0)$. It is also multiplicatively separable over time periods. This means the agent has no income-smoothing desires and only cares about total income less total personal cost, with a zero discount rate. $^{7}$ If the agent chooses not to participate in the agency, he receives a reservation utility of $\underline{U}$.

Let $P\left(x, z_{1}, z_{2} \mid a_{1}, a_{2}\right)$ denote the joint probability of $k, z_{1}, z_{2}$, given the agent's input sequence $t_{1}, a_{2}$. In this section and Section III, we assume:

$$
P\left(x, z_{1}, z_{2} \mid a_{1}, a_{2}\right)=P\left(x \mid a_{1}, a_{2}\right) P\left(z_{1} \mid a_{1}\right) P\left(z_{2} \mid a_{2}\right) \text {, for all } a_{1}, a_{2}
$$

[A 1] entails certain separability about the stochastic environment. In particular, given any input sequence, $x, z_{1}$, and $z_{2}$ are conditionally independent. [A 1] also implies that the agent's choice of $a_{1}$ does not affect the probability of $z_{2}$ and his choice of $a_{2}$ does not affect the probability of $z_{1}$. The latter is natural since $z_{1}$ is realized before $a_{2}$ is chosen.

We label the agent's effort and the output such that high effort in either period produces a higher chance of success, i.e., $P(x=1 \mid H H)>P(x=1 \mid H L)>P(x=1 \mid L L)$ and $P(x=1 \mid H H)>P(x=1 \mid L H)>$ $P(X=1 \mid L L) .{ }^{8}$ Following the agency literature, we assume there is decreasing return to effort such that the Concavity of Distribution Function Condition (CDFC) is satisfied: ${ }^{9}$

$$
\begin{aligned}
& P(x=1 \mid H L)>2 P(x=1 \mid L L)+(1 ! 2) P(x=1 \mid H H) \\
& P(x=1 \mid L H)>2 P(x=1 \mid L L)+(1 ! 2) P(x=1 \mid H H)
\end{aligned}
$$

7 Presumably, one can assume banking opportunities exist and explicitly model the consumption plans for the agent. However, it would create unnecessary distractions for the model (e.g., the information set available to the banker, how the banking market works, etc.). This assumption on the agent's intertemporal tastes is a simple way of sidestepping the distractions. See Fellingham et al. [1985], M alcomson and Spinnewyn [1988] and Fudenberg et al. [1990].

8 We adopt the mnemonic notation $H H$ to represent $H, H$, , and similarly for $H L, L H, L L$.

9 As shown in the proof of proposition 1, with CDFC, input sequence $t, L$, is so unproductive that in designing the optimal labor contract, the principal can ignore the incentive compatibility constraint involving $t$, $L$, once other constraints are satisfied. See Grossman and Hart [1983] for more on the CDFC assumption. 
where $2=1 /(1+\exp (r(c(H))))$

Similarly, we label the news such that high effort produces a higher chance of good news, i.e., $P\left(z_{1}=G \mid a_{1}=H\right)>P\left(z_{1}=G \mid a_{1}=L\right)$ and $P\left(z_{2}=G \mid a_{2}=H\right)>P\left(z_{2}=G \mid a_{2}=L\right)$. Given [A 1], one can "learn more about act $a_{t}$ " from output $x$ and signal $z_{t}$ than from output $x$ alone. Formally, we say $z_{t}$ is incentive informative about $a_{t}$ conditional on $x$. Following Gjesdal [1978], we adopt the following definition of incentive informativeness:

[D1] The information source giving signal $z_{t}$ is said to be incentive informative about act a 0 $\{H, L\}$ conditional on $x$ if $P\left(z_{t} \mid x, H\right) O P\left(z_{t} \mid x, L\right)$ for some $z_{t}$, and some $x$.

Intuitively, an information source is incentive informative about $a_{t}$ if different choices of $a_{t}$ produce different conditional (on $\mathrm{x}$ ) probability of $\mathrm{z}_{\mathrm{t}}$. [A 1] implies $\mathrm{z}_{\mathrm{t}}$ is incentive informative about $\mathrm{a}_{\mathrm{t}}$ conditional on $x(t=1,2){ }^{10}$

Since the agent observes some signal before choosing $a_{2}$, his second-period policy can be thought of as mapping ": \{all possible signals available to the agent before $a_{2}$ is chosen $6\{H, L\}$. Along with his first-period act, the agent's strategy for the entire game can be represented by $t_{1}$, " ,. We assume $q$ is large enough that the principal always prefers the agent to provide high effort in both periods regardless of what information might become available to either party. Thus, the preferred strategy is $H,{ }^{H}{ }_{n}$, , where ${ }^{~ H}$ denotes the second-period policy where high effort is provided for all possible pre- $\mathrm{a}_{2}$ signals. ${ }^{11}$

\section{Principal's Problem (Basic M odel)}

10 In section IV, we will relax [A 1] to allow the $z^{\prime} s$ to be informative about $x$. In general, we think of the $z^{\prime} s$ as representing all possible information within the firms (e.g., internal financial reports, private information about demands and cost structures, etc.). This set of information may be informative about the future payoff (e.g., x) as well as about the managerial actions (i.e., the a's). In this paper, we choose to focus our attention on each of these aspect separately. While considering a more general setting where $z_{t}$ has both attributes (i.e., informative about $x$ and $a$ at the same time) is appealing, it would be hard to tease out the different effects.

11 In general, the optimal labor input is endogenous to the principal's problem. In this paper, we neutralize the production decision in order to focus on the incentive use of accounting information. 
We formulate the principal's problem in our basic model in which only output $\mathrm{x}$ is contractible.

The principal can collapse the three periodic payments into a single payment I(.) at the end of the game because both parties only care about total compensation. Let $\mathrm{E}\left[\mathrm{U}\left(\mathrm{I}(\mathrm{x}) ; \mathbb{\text { ; }} \mathrm{a}_{2}\right.\right.$, "] denote the agent's expected utility if he adopts strategy $\boldsymbol{t}_{1}, "$, , under the payment scheme $I(x)$. To induce $H_{1},{ }^{H}$, , the principal faces the following mechanism design problem:

$$
\begin{aligned}
& C^{*} / \underset{I(x)}{\operatorname{minimum}} E[I(x) \mid H, " H]=E_{x} P(x \mid H H) I(x) \\
& \text { Subject to } E[U(I(x) ; @ H, " H] \$ \underline{U} \\
& E\left[U ( I ( x ) ; @ H , " H ] \$ E \left[U\left(I(x) ; @ a_{1}, "\right] \text { ú } a_{1}, "\right.\right.
\end{aligned}
$$

The principal chooses the best payment plan $I(x)$ to minimize the expected compensation to the agent (expression (1)), subject to the individual rationality (IR) constraint (inequality (2)) and incentive compatibility (IC) constraints (inequalities in (3)). ${ }^{12,13}$ We assume a solution to the optimization problem exists. ${ }^{14} \mathrm{~N}$ otice in the basic model, the private information signals $\left(z_{1}\right.$ and $\left.z_{2}\right)$ do not factor into the mechanism design because they are not contractible and they are conditionally independent of output $\mathrm{x}$.

\section{Section III Accounting Recognition and Moral Hazard}

12 The agent's induced decision tree in the basic model is the following ( $Q$ denotes a decision node for the agent and " denotes the node when a random event is determined by nature):

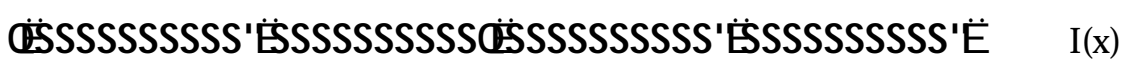 $a_{1},\{H, L\} \quad z_{1} O\{G, B\} \quad a_{2},\{H, L\} \quad z_{2} O\{G, B\} \quad x O\{0,1\}$}

13 To avoid uninteresting cases, we assume the set of possible payment schemes satisfying constraints (2) and (3) is non-empty.

14 See Grossman and $\mathrm{H}$ art [1983] for details on existence. [A 1] and [A 2] imply that when solving the optimization problem, the only IC constraints that can bind are those involving strategies $\mathbf{t}, " \mathrm{H}$, and $+\mathrm{H}$, " L, where " $\left\llcorner\right.$ denotes the second-period policy in which low effort is provided for all possible pre- $a_{2}$ signals. (See the proof of proposition 1.) The IR constraint always binds due to the assumptions on the preferences of the principal and the agent (Holmström and M ilgrom [1987]). 
We now introduce accounting recognition. We show that alternative labor market frictions affect the usefulness of the accounting recognition rules.

\section{Accounting Recognition}

In our setting the recognition issue centers upon when to produce verifiable information that can help the principal control the agent's actions. We consider two recognition rules: one calls for early and the other for late recognition. The early recognition rule, called $R_{1}$, produces an accounting signal denoted $y_{1} O Y /\{1,2\}$ at the end of the first period. Since typically financial accounting numbers are publicly reported and subject to audit, we assume $y_{1}$ is verified, hence contractible. However, $y_{1}$ does not perfectly reveal $z_{1}$ and is only a noisy signal of $z_{1}$. Further, we assume conditional on $z_{1}, y_{1}$ is not informative about any other variables in the model (i.e., the agent's actions $a_{t}$ and the output $x$ ). ${ }^{15}$ The late recognition rule $R_{2}$ produces accounting signal $y_{2} O Y$ at the end of the second period. We assume $y_{2}$ is a noisy signal of both $z_{1}$ and $z_{2}$ in the similar fashion. Formally, $y_{1}$ (resp. $y_{2}$ ) is a garbling of $z_{1}$ (resp. $z_{1}, z_{2}$, .

$$
\begin{aligned}
& y_{1}\left(y_{2}\right) \text { is a garbling of } z_{1}\left(z_{1} \text { and } z_{2}\right) \text {, and } P\left(y_{1}=1 \mid z_{1}=G\right) \text { Ö } P\left(y_{1}=1 \mid z_{1}=B\right) \text {, } \\
& P\left(y_{2}=1 \mid z_{1}=G\right) O \mathscr{P} P\left(y_{2}=1 \mid z_{1}=B\right), P\left(y_{2}=1 \mid z_{2}=G\right) O ̈ P\left(y_{2}=1 \mid z_{2}=B\right)
\end{aligned}
$$

The way we model accounting recognition reflects our attempt to capture the timing aspect of producing accounting information. An accounting information system produces an accounting series (i.e., the $y^{\prime} s$ ) by taking all available information within the firm (i.e., the $z^{\prime} s$ and $x$ ) as inputs and applying an set of accounting recognition rules. ${ }^{16}$ An early recognition rule produces an early signal $\mathrm{y}_{1}$ without the knowledge of $z_{2}$ while the late rule produces the late signal $y_{2}$ with both $z_{1}$ and $z_{2}$ as inputs.

15 Here, accounting merely transmits the agent's private information with some noise but the resulting accounting number is verified, publicly available and therefore contractible. In reality, accounting systems also require some new information to be created in addition to conveying what the agent privately knows. In order to highlight the recognition aspect of accounting, we assume there is no new information generated.

16 If we think of $q A$ as the lifetime cash flow to the firm and the $y^{\prime} s$ as the periodic accounting income, we can preserve the accounting articulation by introducing an "adjusting accrual" $\mathrm{y}_{3}$ in the third period to make sure $y_{t}+y_{3}=q A(t=1,2)$. From an information content point of view, knowing $x$ and $y_{t}, y_{3}$ does not provide any additional information and is clearly redundant in our setting. 
The choice between $R_{1}$ and $R_{2}$ is a choice between early (but less complete) and late (but more complete) information. ${ }^{17}$ However, in producing the $y^{\prime} s$, the accounting system does not completely reveal the underlying private information (the $z^{\prime} s$ ), ${ }^{18}$ so the $y^{\prime} s$ are not as informative as the $z^{\prime} s$.

\section{Principal's Problem with Accounting Recognition}

The principal's contracting problem under $R_{t}$ can be written as the following program:

$$
\begin{aligned}
& C\left(R_{t}\right) / \text { minimum } E\left[I\left(x, y_{t}\right) \mid H, " H\right] \\
& I\left(x, y_{t}\right) \\
& \text { Subject to } E\left[U\left(I\left(x, y_{t}\right) ; \notin H, "{ }^{H}\right] \$ \underline{U}\right.
\end{aligned}
$$

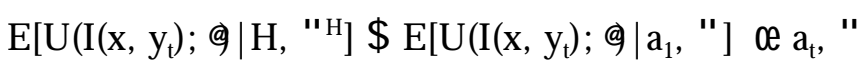

N otice under $R_{1}$ that the strategy set of the agent expands because he can base his second-period input $a_{2}$ on the realizations of accounting signal $y_{1}$ as well as his private signal $z_{1}$ (i.e., the agent's secondperiod policy is a mapping ": $\mathrm{Z} \times \mathrm{Y} 6 \mathrm{~A}){ }^{19}$

A $n$ alternative source of information (to recognition) is to ask the agent to self-report his private information (i.e., the z's). Typically, the principal could design compensation contracts which encourage self reporting by promising to under-utilize the information. There may be Pareto gain from such communication (e.g., Christensen [1981]). However, since the $z$ 's are assumed to be only informative

17 We elaborate on how aggregation occurs in the way we model accounting recognition. It can occur over time. A $n$ accounting system does not always produce information every time some private information is available. Under $R_{1}$ (resp. $R_{2}$ ), accounting is silent when $z_{2}$ (resp. $z_{1}$ ) is known to exist. On the other hand, the aggregation can occur over the realizations of the underlying private signals. Due to the noise in $\mathrm{y}_{\mathrm{t}}$, not all possible realizations of the underlying signals $z_{\mathrm{t}}$ can be uniquely conveyed through the accounting apparatus.

18 There are a number of reason that $y_{t}$ is not fully revealing. A ccounting chooses to ignore a number of relevant information pieces (i.e., internally generated goodwill). M anagement may choose to exclude certain information from the financial statements.

19 The agent's induced decision trees under $R_{1}$ and $R_{2}$ are:

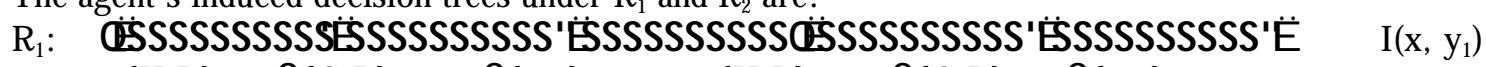
$a_{1},\{H, L\} \quad z_{1} O\{G, B\} \quad y_{1} O\{1,2\} \quad a_{2},\{H, L\} \quad z_{2} O\{G, B\} \quad x O\{0,1\}$

$$
\begin{aligned}
& R_{2} \text { : ÀSSSSSSSSSS"ÀSSSSSSSSSSÀSSSSSSSSSS"ÀSSSSSSSSSS"ÀSSSSSSSSSS"À I } \quad \mathrm{I}\left(\mathrm{x}, \mathrm{y}_{2}\right) \\
& a_{1},\{H, L\} \quad z_{1} O\{G, B\} \quad a_{2},\{H, L\} \quad z_{2} O\{G, B\} \quad y_{2} O\{1,2\} \quad x O\{0,1\}
\end{aligned}
$$


about the actions (the a's) and not informative about the stochastic environment (i.e., the z's are assumed to be independent of $x$ ). A self-report will not be useful to the principal. We relax the independence assumption and study the communication setting formally in Section IV .

\section{Usefulness of Accounting R ecognition}

The principal weakly prefers accounting recognition $R_{t}$ to no recognition, i.e., $C\left(R_{t}\right) \# C^{*}(t=1$, 2). Clearly, the principal can always choose (and commit) not to use the additional information generated by the accounting recognition and resort to the optimal contract in the basic model. ${ }^{20}$ (The original optimal contract is feasible in the expanded program.) So in our setting, early (late) recognition is strictly valuable (relative to no recognition) if contracting on $y_{1}\left(y_{2}\right)$ reduces the principal's ex ante expected payment to the agent in equilibrium.

Proposition 1: Assume [A 1], [A 2], and [A 3], then:

(i) $P(x=1 \mid L H)>P(x=1 \mid H L)$ implies early and late recognition rules are strictly valuable to the principal; and

(ii) $\mathrm{P}(\mathrm{x}=1 \mid \mathrm{LH})<\mathrm{P}(\mathrm{x}=1 \mid \mathrm{HL})$ implies late but not early recognition rule is strictly valuable to the principal.

When $P(x=1 \mid L H)>P(x=1 \mid H L)$, shirking in the first period (i.e., $t, "{ }^{\prime}$, ) is "less likely to be detected" than shirking in the second period (e.g., $+\mathrm{H}$, "L, ). In turn, the principal is more concerned with the agent supplying low effort in the first period than in the second period. In this case, both early and late recognition rules are valuable because both $y_{1}$ and $y_{2}$ are generally incentive informative about $a_{1}$ conditional on output $x$. Which is better, early or late recognition, depends upon the relative informativeness of the $y^{\prime} s$ about $z_{1}$. Under the restrictive condition that $y_{2}$ is independent of $z_{1}$, we have the stronger result that only early recognition is useful.

20 In general, when pre-decision information (i.e., $y_{1}$ before $a_{2}$ ) is introduced, this commitment argument does not follow. However, it does here because $y_{1}$ is a garbling of $z_{1}$, which is available to the agent regardless. W ith no recognition, the agent's second period strategy is the mapping ": $Z 6 \mathrm{~A}$. With recognition of $y_{1}$, the mapping is ": $Z \times Y 6 A$. If the principal commits not to use $y_{1}$, the agent can not gain by conditioning his second period act $\left(\mathrm{a}_{2}\right)$ non-trivially on $\mathrm{y}_{1}$. 
When $P(x=1 \mid L H)<P(x=1 \mid H L)$, the principal is more concerned with the agent supplying low effort in the second period. Here only late recognition is valuable because $y_{2}$ is incentive informative about $\mathrm{a}_{2}$ conditional on $\mathrm{x}$ while $\mathrm{y}_{1}$ is not. In short, the principal's preference over $\mathrm{R}_{1}$ and $\mathrm{R}_{2}$ depends upon which moral hazard problem $\left(a_{1}\right.$ or $\left.a_{2}\right)$ is more critical. ${ }^{21}$

Delayed output realization, among other features, contributes to the above result. In the basic model, output $x$ is used to control the agent's labor inputs in both periods. Technically, this implies that, in the basic model, the two relevant IC constraints involving $H, " L$, and $t, " H$, are nested. W ith our binary structure, each constraint essentially imposes a "steepness requirement" on the incentive scheme. A s a result, only the steeper of the two requirements is in effect, leaving the other IC constraint inactive (or not binding). ${ }^{22} \mathrm{~N}$ aturally, if the IC constraint involving $t, " H$, is inactive, information about $\mathrm{a}_{1}$ is useless. This is in contrast to repeated moral hazard models (e. g., L ambert [1983], Rogerson [1985], Radner [1985], M alcomson and Spinnewyn [1988], and Fudenberg et al. [1990]) where periodic output is observed between the agent's labor inputs, and long-term effects are typically neutralized. Therefore, the issue of nested IC constraints is not present. ${ }^{23}$

21 Earlier studies of informativeness criterion in agency settings (e. g., Holmström [1979]) and Kim [1995]) worked with a single IC constraint. Here, there are two IC constraints that may bind. A signal's informativeness about the agent's act may not guarantee its usefulness in contracting because the IC constraint with respect to that act may not bind.

22 There is an issue of redundant constraints here. If $P(x=1 \mid H L)=P(x=1 \mid L H)$, the two IC constraints are identical and one is clearly redundant. Technically, it causes an indeterminancy of the Lagrange multipliers associated with the two IC constraints. If this is the case, the rank condition in the ArrowHurwicz-U zawa theorem is not satisfied (Takayama [1974]). This rank condition is a sufficient condition for the validity of characterizing the solution using the Kuhn-Tucker conditions. To avoid complicating the matter, we simply assume $P(x=1 \mid L H)$ ÖP $(x=1 \mid H L)$ to satisfy the rank condition.

In the general case of more than two input choices or a continuum of inputs, desirable labor input choice (i.e., which act to induce) becomes an non-trivial issue. Interactions between input choice and incentive design become relevant. In this paper our focus is on incentive issues, so we purposely fixed desirable action choice.

23 In repeated moral hazard models cited, the agent's action in each period only affects the output of that particular period (i.e., no long-run effects). Typically, each period's IC constraint binds individually. 
The interaction among nested IC constraints is also present in Demski [1994]. In his singleperiod-multiple-task setting, certain IC constraint may "free ride" other IC constraints. The interaction "between the problem of motivating input for the task pe se and the problem of coordinating supply of inputs across the array of tasks" (Demski [1994], p. 577) may result in "good" performance measures driving out "bad" measures or "bad" driving out "good" measures. In our multi-period setting, a similar force is in play.

\section{Discussion}

The key idea in this section is that the optimal recognition rule is affected by the nature of labor market frictions. "When to recognize" depends upon which of the two labor inputs poses a more critical incentive problem.

The notion of critical event has played an important role in recognition debates since $\mathrm{M}$ yers [1959] first introduced such a concept. Take revenue recognition as an example. U sually, some critical event, such as a transfer of merchandise, must occur to trigger revenue recognition. M ost of the literature treats uncertainties associated with the major events in the earning process as the focus of the recognition issue (e.g., Johnson and Storey [1983]); the control aspect of these events is not at center stage.

This paper stresses moral hazard concerns in the recognition debate. When control is a viable concern, the optimal time to produce information about managerial actions is not when the most uncertain event in the earning process has occurred, but when the critical labor input appears. To illustrate, suppose $P(x=1 \mid L H)<P(x=1 \mid H L)$, we can infer that first-period labor input $a_{1}$ is marginally more productive than second-period input $a_{2}$. If we treat labor inputs as purely random events (i.e., no control problem is present), the critical event in this earning process occurs in the first period in the sense that

knowing $a_{1}$ leaves less uncertainty about future cash flow $x$. However, in the presence of moral hazard, Proposition 1 tells us that information about $a_{1}$ is useless while information about $a_{2}$ is valuable. 
Therefore, the critical event occurs in the second period. In short, the critical event in valuation settings can be different from that in agency settings. ${ }^{24}$

\section{Section IV Accounting R ecognition and Veracity Check}

In this section, we consider a setting where the agent's private signals are informative about the realization of output $x$. Communicating such information (e.g., a self-report on $z_{t}$ by the agent) can reduce agency costs (e.g., Christensen [1981], Penno [1984], and M elumad and Reichelstein [1987]). We study the role of accounting recognition in such a communication regime. In the previous section, accounting signals were used to control the agent's labor inputs. In this section, they are used to control the agent's self-report as well.

When signal $z_{t}$ is informative about the output $x$, we say it is valuation informative. Following Gjesdal [1978], we adopt the following definition: ${ }^{25}$

[D2] The information source giving signal $z_{t}$ is said to be valuation informative about future cash flow $x$ conditional on signal $T$ in the presence of input sequence $t_{1}, a_{2}$, if $P\left(z_{t}\right) \times N$ $\left.\mathrm{T}, \mathrm{a}_{1}, \mathrm{a}_{2}\right)$ ÖP $\left(z_{t} \mid \times \mathrm{Q} \mathrm{T}, \mathrm{a}_{1}, \mathrm{a}_{2}\right)$ for some $\times \mathbf{O O} \times \mathrm{Q}$ some $z_{\mathrm{t}}$, and some $\mathrm{T}$.

In our context, the conditioning information source $T$ may refer to other $z_{t}$ or the accounting signal $y_{t}$. Intuitively, $z_{t}$ is valuation informative about $x$ if $z$ is not independent of $*, T$, for a given input sequence. [A 1] clearly precludes $z_{t}$ from being valuation informative about $x$ because it assumes

24 We use a numerical example to elaborate. $L$ et $P(x=1 \mid H H), P(x=1 \mid H L), P(x=1 \mid L H)$, and $P(x=1 \mid L L)$ be $0.8,0.7,0.6$, and 0.3 respectively. Suppose the labor inputs are purely random (1/4 probability for all four combinations). The prior probability $P(S)$ is $.6(=(.8+.7+.6+.3) / 4)$. If $a_{1}=H$, the posterior $P\left(x=1 \mid a_{1}=H\right)=(.8+.7) / 2=.75$; and similarly if $a_{1}=L, P\left(x=1 \mid a_{1}=L\right)=.45$. Changes from prior are \pm .15 . On the other hand, knowing $a_{2}$ only changes the prior by \pm .10 . Therefore, $a_{1}$ can be thought of as "the most uncertain event" in the earning process because knowing the realization of $a_{1}$ changes the posterior probability the most. However, if the agent's acts are not random but subject to moral hazard, by Proposition 1 we know (since $P(x=1 \mid L H)<P(x=1 \mid H L)$,) the useful information is about $a_{2}$, not $a_{1}$.

25 Notice in our context, consumption decisions are neutralized. Therefore, valuation informativeness is defined without reference to a decision context and is purely from a probabilistic point of view. 
independence among $x, z_{1}$, and $z_{2}$ for all input sequences. We replace [A 1] with two assumptions. First, we assume:

$$
\begin{aligned}
& P\left(z_{t} \mid a_{1}, a_{2}\right)=P\left(z_{t}\right) \text { for all } t_{1}, a_{2}, t=1,2 \text {; and } \\
& P\left(z_{1}, z_{2} \mid x, a_{1}, a_{2}\right)=P\left(z_{1} \mid x, a_{1}, a_{2}\right) P\left(z_{2} \mid x, a_{1}, a_{2}\right)
\end{aligned}
$$

The agent's labor input choice does not affect the probability of $z_{t}$ and private signals $z_{1}$ and $z_{2}$ are conditionally independent. ${ }^{26}$ In addition to [A 4], we assume for all $\mathrm{z}_{\mathrm{t}}$ :

$$
\begin{aligned}
& P\left(x \mid z_{t}=G, a_{1}, a_{2}\right) \text { ÖP }\left(x \mid z_{t}=B, a_{1}, a_{2}\right) \text { when } t_{1}, a_{2},=H, H, ; \\
& P\left(x \mid z_{t}, a_{1}, a_{2}\right)=P\left(x \mid a_{1}, a_{2}\right) \text { when } t_{1}, a_{2},=H, L, t, H, t, L,
\end{aligned}
$$

Under [A 5], $z_{1}$ and $z_{2}$ are valuation informative about $x$ only when the agent provides high effort in both periods. When the agent supplies low effort in either period, $x, z_{1}$, and $z_{2}$ are mutually independent (in fact $z_{1}$ and $z_{2}$ reduce to pure noise). ${ }^{27}$ One can interpret [A 5] as a complementarity effect among the two factors of production (i.e., the agent's efforts and the information content of the signals). If the agent works hard, he is likely to receive forward-looking information. If he shirks, his information is not valuation informative about $x .^{28}$

26 This assumption is part of our experimental design, which isolates the valuation informativeness (and therefor the veracity check role) of accounting information. As noted earlier, a self-reported $z_{t}$ that is only incentive informative about $a_{t}$ is not useful to the principal. If $z_{t}$ is also incentive informative about $a_{t}$, then accounting signal $y_{t}$ is also incentive informative about $a_{t}$ when $z_{t}$ is not known. It will be hard to tell whether the usefulness of $y_{t}$ is attributed to its valuation informativeness (about $x$ ) or its incentive informativeness (about $a_{t}$ ). By making [A 4], we remove the interaction between the two types of informativeness of $z_{t}$ and streamline the analysis.

27 [A 5] simplifies the derivation of the sufficient conditions for communication to be strictly preferred (Observation 1). However, Proposition 2, the more important result, does not rely on [A 5].

28 We give a numerical example of such a joint probability $P\left(x, z_{1} \mid a_{1}, a_{2}\right)$ structure. Consider the following:

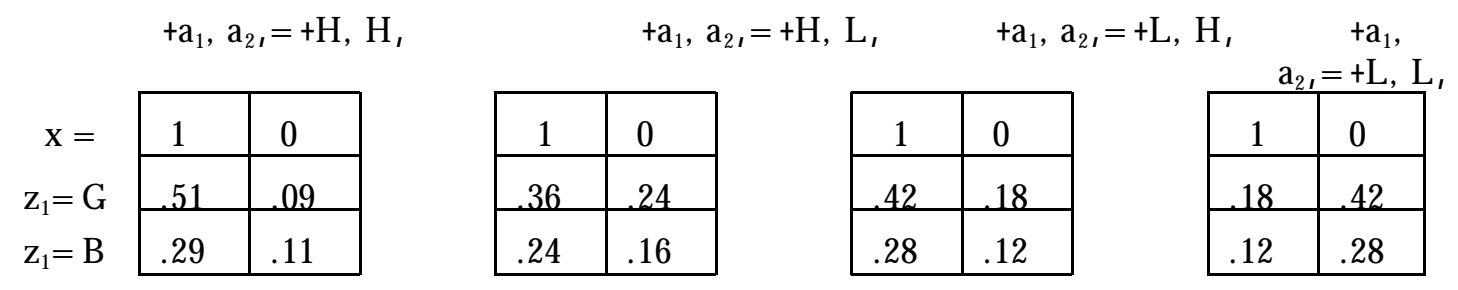

Consistent with [A 4], $P\left(z_{1}=G \mid a_{1}, a_{2}\right)=P\left(z_{1}=G\right)=.6$. [A 5] is also readily verified. The joint probability 


\section{Principal's Problem}

Turning to the contracting problem with communication, we focus on a setting where a single message is reported by the agent immediately after he privately observes $z_{1}$. Therefore, the agent's selfreporting strategy is a mapping $m: Z 6 z$, with $m\left(z_{1}\right)$ denoting the message reported when $z_{1}$ is observed. Relying on the Revelation Principle, we restrict our attention to truth-telling mechanisms. ${ }^{29} \mathrm{~N}$ otice under both recognition regimes $\left(R_{1}\right.$ and $\left.R_{2}\right)$, accounting signal is produced subsequent to the self-report $m($.$) .$ Let $\mathrm{m}^{\top}$ denote the truth-telling reporting strategy and let $E\left[U\left(I\left(x, y_{t}, m(A) ; @ a_{1}, m\right.\right.\right.$, " ] denote the agent's expected utility if he supplies input sequence $\mathbf{t}_{1,}$, , and adopts reporting strategy $m$ under payment scheme $I\left(x, y_{t}, m(A)\right.$. The mechanism design program for the principal can be written as:

$$
C\left(R_{t}, m\right) / \underset{I(\mathbb{A}}{\operatorname{minimum}} E\left[I\left(x, y_{t}, m\left(z_{1}\right)\right) \mid H, m^{\top},{ }^{H}\right]
$$

$$
\begin{aligned}
& \text { Subject to } E\left[U \left(I\left(@ @ H, m^{\top}, " H\right] \$ \underline{U}\right.\right. \\
& E\left[U \left(I ( @ \bigotimes H , m ^ { \top } , " H ] \$ E \left[U \left(I\left(@ @ a_{1}, m, "\right] \text { ú } a_{1}, m, " ~\right.\right.\right.\right.
\end{aligned}
$$

The incentive scheme I (@s now a collection of contingent payment schemes indexed by the agent's message $m\left(z_{1}\right)$. Effectively, the payment schedule depends upon $m\left(z_{1}\right)$, as well as the public information $\mathrm{x}$ and $\mathrm{y}_{\mathrm{t}}$. Notice the set of IC constraints (inequalities in (9)) also includes the truth-telling constraints. ${ }^{30}$

structure of $x$ and $z_{2}$ can be constructed similarly.

29 Two conditions are assumed: (1) full communication is costless; (2) the principal has commitment power. See M yerson [1979] and Harris and Townsend [1981] for more on the Revelation Principle.

30 With communication, the agent's induced decision trees under $R_{1}$ and $R_{2}$ are:

$\mathrm{R}_{1}$ : ÀSSSSSSSS"ÀSSSSSSSSÀ̇SSSSSSSS"ÀSSSSSSSSQ̇̀SSSSSSSS"ÀSSSSSSSS"À I $\left(\mathrm{x}, \mathrm{m}, \mathrm{y}_{1}\right)$ $a_{1},\{H, L\} \quad z_{1} O\{G, B\} \quad m\left(z_{1}\right) O\{G, B\} \quad y_{1} O\{1,2\} \quad a_{2},\{H, L\} \quad z_{2} O\{G, B\} \quad x O\{0,1\}$

$R_{2}$ : ÀSSSSSSSS"ÀSSSSSSSSÀSSSSSSSSÀ̀SSSSSSSS"ÀSSSSSSSS"ÀSSSSSSSS"À I $\left(x, m, y_{2}\right)$ $a_{1},\{H, L\} \quad z_{1} O\{G, B\} \quad m\left(z_{1}\right) O\{G, B\} \quad a_{2},\{H, L\} \quad z_{2} O\{G, B\} \quad y_{2} O\{1,2\} \quad x O\{0,1\}$ 


\section{Demand For Veracity Check}

We begin with the case in which neither $y_{1}$ nor $y_{2}$ is recognized. In this case, the agent issues a self-report on $z_{1}$ and the two parties contract on $x$ and $m(.)^{31}$

Observation 1: Assume [A 2], [A 4], [A 5] and no recognition, communication of $z_{1}$ is strictly valuable if

(i) $P(x=1 \mid L H)>P(x=1 \mid H L)$; and

(ii) $\frac{\mathrm{P}(\mathrm{x}=1 \mid \mathrm{HH}) \mathrm{P}(\mathrm{x}=0 \mid \mathrm{LH})}{\mathrm{P}(\mathrm{x}=1 \mid \mathrm{LH}) \mathrm{P}(\mathrm{x}=0 \mid \mathrm{HH})}<\frac{\mathrm{P}\left(\mathrm{x}=1 \mid \mathrm{z}_{1}=\mathrm{G}, \mathrm{HH}\right) \mathrm{P}\left(\mathrm{x}=0 \mid \mathrm{z}_{1}=\mathrm{B}, \mathrm{HH}\right)}{\mathrm{P}\left(\mathrm{x}=1 \mid \mathrm{z}_{1}=\mathrm{B}, \mathrm{HH}\right) \mathrm{P}\left(\mathrm{x}=0 \mid \mathrm{z}_{1}=\mathrm{G}, \mathrm{HH}\right)}$

Intuitively, the two conditions appeal to mutual gains through communication. Under condition (i), the only binding IC constraint involves $t, "{ }^{H}$, absent communication. This gives the principal more flexibility in designing the optimal contract. Condition (ii) requires that the probability revision caused by $z_{1}$ is large enough to make the communication worthwhile. ${ }^{32}$ Observation 1 merely identifies a parameter region where communication is strictly valuable. The value of communication in agency settings has been established by previous studies mentioned before (Christensen [1981] etc.).

W e give the following numerical example to illustrate Observation 1. Suppose, $P\left(z_{1}=G\right)=.6$, $P\left(x=1 \mid z_{1}=G, H H\right)=.85, P\left(x=1 \mid z_{1}=B, H H\right)=.725, P(x=1 \mid L H)=.7, P(x=1 \mid H L)=.6$, $P(X=1 \mid L L)=.3, C(L)=0, c(H)=2,000, r=.0001$, and $\underline{U}=! \exp (! r 15,000)$. W ithout communication, the expected payment to the agent is 21,640 . W ith a self-report on $z_{1}$, the expected payment is $21,542 .{ }^{33}$ Notice condition (i) and (ii) in the observation can be verified: (i) $P(x=1 \mid L H)=.7>P(x=1 \mid H L)=.6$; and (ii) $(.8)(.3) /((.7)(.2))=1.714<(.85)(.275) /((.725)(.15)=2.149$.

31 The agent's decision tree in this special case is:

\section{À̀SSSSSSSSS"ÀSSSSSSSSSSCìSSSSSSSSSCÀSSSSSSSSSS"ÀSSSSSSSSSS"À I(x, m)} $a_{1},\{H, L\} \quad z_{1} O\{G, B\} \quad m\left(z_{1}\right) O\{G, B\} \quad a_{2},\{H, L\} \quad z_{2} O\{G, B\} \quad x O\{0,1\}$

32 This is similar to the notion of information gap in Christensen [1981].

33 The payment schedule for the case with no communication is I $(x=1)=24,848 ; I(x=0)=8,807$ and with communication, $I(m=G, x=1)=25,020 ; I(m=G, x=0)=8,671 ; I(m=B, x=1)=24,110$; and I $(m=B, x$ $0)=9,173$. 
When communication is strictly valuable, accounting recognition is useful as long as $\mathrm{y}_{\mathrm{t}}$ reveals something about the realization of $z_{1}$. In other words, there exists a strict demand for a veracity check for the earlier self-report.

Proposition 2: Assume [A 2], [A 3], [A 4], and that communication is strictly valuable, both recognition rules $\left(R_{t}, t=1,2\right)$ are strictly valuable to the principal.

Recall that accounting signal $\mathrm{y}_{1}$ (resp. $\left.\mathrm{y}_{2}\right)$ is at best a garbling of the agent's private signal $\mathrm{z}_{1}$ (resp. $z_{1}, z_{2}$,). Normally when $y_{t}$ is a garbling of $z_{1}$, contracting on $y_{t}$ is not useful when $z_{1}$ is al ready used in the contract. In our setting, however, $z_{1}$ is self-reported through $m\left(z_{1}\right)$, and the self-reporting is subject to additional (induced) moral hazard. ${ }^{34}$ In turn, contracting on accounting signal $\mathrm{y}_{\mathrm{t}}$ helps the principal combat the moral hazard associated with the self-reporting. Should he choose to lie in his

report (i.e., $m\left(z_{1}\right) \mathrm{O}_{1}$ ), the agent runs the risk of being "punished" by the upcoming accounting report. This disciplining role is what makes $\mathrm{y}_{\mathrm{t}}$ valuable for the principal.

\section{Discussion}

In general, an entity's accounting report and the voluntary disclosure by its managers are both useful to its stakeholders. In our setting, both the accounting signal $\left(y_{t}\right)$ and the self-report $\left(m\left(z_{1}\right)\right)$ help the principal mitigate his contracting problem. M ore importantly, the two sources of information complement each other as well. The self-report has the comparative advantage of being early and having the ability to predict $x$. However, it lacks trustworthiness because, if not controlled, the agent has the incentive to lie to his advantage. On the other hand, the accounting signal may not be valuation informative about $x$ conditional on a truthfully reported $z_{1}$ by the agent. But it has the advantage of being a veracity check on the agent's earlier self-report because the typical accounting report is subject to audit

34 The moral hazard on reporting is induced because any misreporting pe se does not factor into the agent's utility. The agent has no incentive to lie just for the sake of lying. However, the agent is also asked to provide unobservable, and personally costly, labor inputs, as well as the report. 
and there is no (or considerably less) incentive problem associated with this source. ${ }^{35}$ This is the key to understanding the usefulness of accounting information in our context.

This result has implications for the different functions served by accounting. In empirical research, especially event studies, earnings announcements fail to explain a large part of security price movement, and this is interpreted as suggesting, if not implying, accounting reports lack usefulness (e.g., Lev [1989]). In this paper, however, accounting is useful not for its expediency in providing timely valuation information to the security market, but for its ability to provide a veracity check on other, unaudited sources of information. These other sources (e.g., the manager's self-report) are more readily controlled because there is a pending, undisputable accounting report. Therefore, the noted empirical regularity does not necessarily imply the lack of usefulness of accounting information. In fact, limited reaction to the accounting report is expected in equilibrium. Timeliness (early production and dissemination of information) is not necessarily a virtue for accounting as a source of information. Delaying an accounting report can enhance the disciplining role of accounting (through the auditing process). This paper highlights credibility as the key characteristics of accounting. The principal can use accounting report readily while she must control the self-report (through additional truth-telling IC constraints). The usefulness of accounting comes from its disciplining function through labor contracting. ${ }^{36}$

35 The auditing process and the reputation management by the accounting professionals are outside of this model. We take the easy route of assuming that they result in no incentive problems associated with these professionals. But it is by no means implied that the process and behavior are unimportant. In fact, they are critical to the result.

The growing literature on earnings management has indicated that managers have, on the margin, some control over the accounting reports. This possibility is absent in this paper. Our current focus is the interaction between audited accounting reports and other, unaudited sources of information.

36 Here the disciplining function is through formal contracting, which is a modeling convenience. In practice, the disciplining may be achieved through managerial reputation and retention, etc. The focus of this study is on the disciplining function, not the form of the disciplining function. 


\section{Communication and Optimal Recognition}

Finally, we examine how the presence of the earlier communication changes the usefulness of al ternative recognition rules. We have established that communication gives rise to an additional role of credible accounting information (i.e., veracity check). Now we probe further to see whether this additional role makes early or late recognition more or less attractive.

Proposition 3: Assume [A 2], [A 3], [A 4] and that communication is strictly valuable, there exists a parameter region with positive measure in which early recognition is strictly preferred when no communication is allowed but late recognition is strictly preferred when communication is allowed.

We use a series of numerical examples to illustrate Proposition 3 to see how the presence of communication may prompt the principal to favor the late recognition rule $\left(R_{2}\right)$. We continue with the numerical specifications from the last numerical example; in addition, suppose $z_{2}$ is such that $P\left(z_{2}=G\right)=0.5$ and $P\left(x=1 \mid z_{2}=G, H H\right)=0.82$. U nder $R_{1}, y_{1}$ is a garbling of $z_{1}$ with $P\left(y_{1}=2 \mid z_{1}=G\right)=.8$ and $P\left(y_{1}=2 \mid z_{1}=B\right)=.05$. Under $R_{2}, P\left(y_{2}=2 \mid z_{2}=G\right)=.65$ and $P\left(y_{2}=2 \mid z_{2}=B\right)=.35$. In Figure 2, we plot the four expected payments $S C\left(R_{1}\right), C\left(R_{2}\right), C\left(R_{1}, m\right)$, and $C\left(R_{2}, m\right)$ for different values of conditional probability $0 / \mathrm{P}\left(\mathrm{y}_{2}=2 \mid \mathrm{z}_{1}=\mathrm{G}\right)$ with $00[.5, .8]$. Intuitively, higher 0 means $\mathrm{y}_{2}$ conveys "more information" about $\mathrm{z}_{1}$.

A bsent communication $C\left(R_{2}\right)$ decreases in 0 as "more information" about $z_{1}$ is available with higher 0 . N aturally, $C\left(R_{1}\right)$ is a constant as the stochastic property of $y_{1}$ does not change with 0 . W ith communication, $C\left(R_{2}, m\right)$ and $C\left(R_{1}, m\right)$ display a similar pattern. Examination of Figure 2 shows that in the parameter region where 0 ranges from approximately . 70 to .775 , communication makes delaying accounting recognition optimal (i.e., $R_{1}$ is preferred absent communication and $R_{2}$ is preferred with communication).

To understand the intuition behind this result, recall that incentive informativeness has been removed by assumption [A 4]. The only benefit from producing additional information (either through accounting signals $y_{t}$ and/or the self-report $m\left(z_{1}\right)$ ) is derived from early read on output $x$ to improve the 
contracting. In these examples, both $z_{1}$ and $z_{2}$ are valuation informative about $x$. Therefore under early recognition, accounting signal $y_{1}$, correlated with $z_{1}$, is informative about $x$ through the fact $z_{1}$ is informative about $x$. A nd under late recognition, the accounting signal $y_{2}$, correlated with both $z_{1}$ and $z_{2}$, is informative about x through two independent "channels:" (1) the fact $z_{1}$ is informative about $x$; and (2) the fact $z_{2}$ is informative about $x$.

In the interesting parameter region, without communication, $R_{1}$ is preferred because the the principal can infer more about $x$ from $y_{1}$ than from $y_{2}$. With communication, under both recognition regimes, $z_{1}$ is, in equilibrium, revealed truthfully, which provides information about $x$. With $R_{1}, y_{1}$ is used only to discipline the self report $m\left(z_{1}\right)$; but with $R_{2}, y_{2}$ does two jobs: (1) disciplining $m\left(z_{1}\right)\left(y_{2}\right.$ is correlated with $z_{1}$ ); and (2) providing additional information about $x$ since $y_{2}$ is also correlated with $z_{2}$ (and $z_{2}$ is valuation informative about $x$ independently of $z_{1}$ ). W ith $z_{1}$ truthfully communicated, more is known about $\mathrm{x}$ with $\mathrm{y}_{2}$ than with $\mathrm{y}_{1}$ so the principal is willing to tolerate some noise in $\mathrm{y}_{2}$ about $\mathrm{z}_{1}$ (i.e. , the disciplining role). Here, the benefit of the additional information about $x$ out-weights the cost of noise.

The key idea shown in these numerical examples is that other information sources (e.g., the manager's self-report) interact with the accounting source. Therefore, when evaluating al ternative recognition rules, one must keep in mind this interactive effect among the proposed recognition rule and other sources of information. In this instance, the presence of other information makes delaying the accounting recognition optimal.

The opposite of Proposition 3 may also be true. In other words, there exist a set of parameters that late recognition is strictly preferred when no communication is allowed but early recognition is strictly preferred when communication is allowed. ${ }^{37}$ We have not considered soliciting a second self-

37 Here are the specifics of the counter-example: set $P\left(y_{1}=2 \mid z_{1}=G\right)=.7$ and $P\left(y_{1}=2 \mid z_{1}=B\right)=.2$ and keep everything else the same the examples in the text. At $0=.56$, we have $C\left(R_{1}\right)=21,359, C\left(R_{2}\right)=21,337$, $C\left(R_{1}, m\right)=21,264$, and $C\left(R_{2}, m\right)=21,312$. 
report (on $z_{2}$ ) from the manager. Since $z_{2}$ is informative about the outcome $x$, we expected such communication can be valuable (Christensen [1981], etc.). The demand for a later veracity check may al so exist. However, introducing a second self-report may further complicate the model. Christensen and Feltham [1997] study sequential vs. simultaneous self-reports in an agency setting with two private signals and Farlee [1998] studies timely vs. delayed self-reports in similar settings.

\section{Section V Conclusions}

In accounting theory and practice, recognition issues have been controversial. We seek to enrich the debate by acknowledging the incentive use of accounting information and the interaction between accounting and other information sources. We cast a recognition choice problem in a stewardship framework and allow other information sources into the picture. We see that the optimal recognition choice depends on whether the moral hazard at the proposed recognition time is critical, not whether the most uncertainty about the earning process has been resolved. When we allow other information sources into the model, the veracity check role of accounting surfaces in our analysis. Finally, the presence of other information may call for later recognition.

In our model, the contracting and the confirmatory roles of accounting are highlighted. We see these two roles as the comparative advantage of accounting as a source of information. Accounting is valuable to the extent that it is credible, comprehensive, and subject to careful and professional judgment. Naturally, this makes accounting information a perfect candidate for contracting and confirmatory uses. ${ }^{38}$ While other information sources may be more timely in providing valuation information about an entity, audited accounting information, when used in explicit or implicit contracts, helps ensure the accuracy of the reports from other sources.

Gigler and Hemmer [1998] also emphasizes the confirmatory role of financial accounting reports. 
Tractability concerns clearly limit the analysis. As an interesting extension of the study, we can allow the agent to have partial control over the accounting apparatus. This will enable us to examine the accounting structure in the more realistic setting where performance manipulations may exist. 
Figure 1: Sequence of E vents
$t=1$
$t=2$
$t=3$

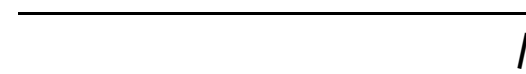

l 1

I

/

/

agent's inputs

$a_{1} O\{H, L\}$

$\mathrm{a}_{2} \mathrm{O}\{\mathrm{H}, \mathrm{L}\}$

agent's private

information

$\mathrm{Z}_{1} 0\{\mathrm{G}, \mathrm{B}\}$

$\mathrm{Z}_{2} O\{\mathrm{G}, \mathrm{B}\}$

output

$\times 0\{0,1\}$

accounting recognition rules:

early: $R_{1}$

late: $R_{2}$

agent's net compensation

principal's net cash flow $\mathrm{y}_{1} 0\{1,2\}$

$\mathrm{n} / \mathrm{a}$

$\mathrm{I}_{1} ! c\left(\mathrm{a}_{1}\right)$

$\mathrm{I}_{1}$

$$
\begin{gathered}
\mathrm{n} / \mathrm{a} \\
\mathrm{y}_{2} 0\{1,2\} \\
\mathrm{I}_{2} ! c\left(a_{2}\right)
\end{gathered}
$$$$
I_{3}
$$

$! I_{2}$

$\mathrm{qA} ! \mathrm{I}_{3}$ 
Figure 2: Expected Payments under Alternative Recognition Rules

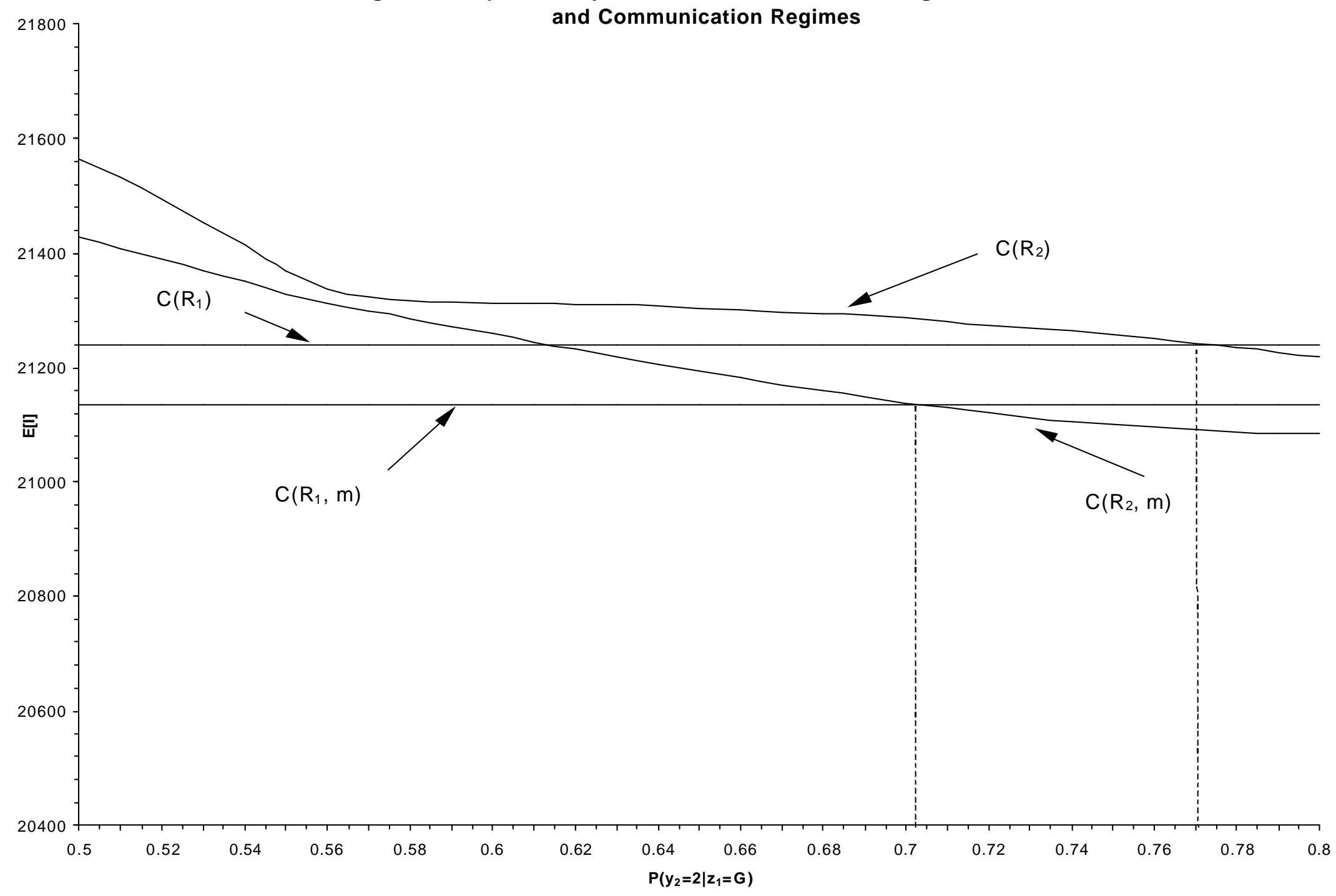




\section{Reference}

A lexander, S. S. "Income M easurement in a Dynamic Economy." In Studies in Accounting Theory, edited by W. T. Baxter and Sidney Davidson. Homewood, IL: Richard D. Irwin, Inc., 1962.

A merican A ccounting A ssociation Concepts and Standards Research Committee. "The Realization Concept." Accounting Review (1965): 312-322.

A ntle, R., J. S. Demski, and S. G. Ryan. "M ultiple Sources of Information, V aluation, and A ccounting Earnings." J ournal of Accounting, Auditing \& Finance (1994): 675-696.

A ntle, R., and A. Smith. "M easuring Executive Compensations: M ethods and an A pplication." J ournal of Accounting Research (Spring 1985): 1-39.

A ntle, R., and J. S. Demski. "Revenue Recognition." Contemporary Accounting Research (Spring 1989): 423-451.

Beaver W., H. "The Information Content of A nnual Earnings A nnouncements." J ournal of Accounting Research (1968 supp): 67-92.

Beaver, W. H., and S. G. Ryan. "Accounting Conservatism and Delayed Recognition and their Effects on the A bility of the Book-to-M arket Ratio to Predict Book Return on Equity and Security Return." W orking paper 1995.

Butterworth, John E. "The A ccounting System as an Information Function. " J ournal of Accounting Research (1972): 1-27.

Canning, J. B. The Economics of Accountancy. New Y ork, NY: Ronald Press, 1929.

Christensen, J. "Communication in A gencies." Rand J ournal of E conomics (A utumn, 1981): 661-674.

Christensen, P., and G. A. Feltham, "Sequential Communication in A gencies." Review of Accounting Studies (1997): 123-155

Demski, J. S. Information Analysis. A ddison-W esley, 1972.

Demski, J. S. M anagerial U se of Accounting Information. Norwell, M A: Kluwer A cademic Publishers, 1997.

Edwards, E. O., and P. W. Bell. The Theory of M easurement of Business Income. Berkeley, California: University of California Press, 1961.

Farlee, M., "Welfare Effects of Timely Reporting," Review of Accounting Studies (1998): 289-320.

Fellingham, J., P. N ewman, and Y. Suh, "Contracts without M emory in M ultiperiod A gency M odels," J ournal of Economic Theory, (1985): 340-355.

Feltham, G. Information Evaluation. Sarasota, Florida: A merican A ccounting A ssociation, 1972. 
Feltham, G., and J. Xie, "Performance M easure Congruity and Diversity in M ulti-Task Principal/A gent Relations." Accounting Review (1994): 429-53.

Financial A ccounting Standards Board. Statements of Financial Accounting Concepts. Burr Ridge, IL: Irwin, 1994.

Fudenberg, D., B. Holmström, and P. M ilgrom, "Short-T erm Contracts and L ong-Term A gency relationship." J ournal of Economic Theory, (1990): 1-31.

Gigler, F., and T. Hemmer, "On the Frequency, Quality, and Informational Role of M andatory Financial Reports." J ournal of Accounting Research (Supp. 1998): 117-147

Gjesdal, F. "Accounting for Stewardship." J ournal of Accounting Research (A utumn, 1981): 208-231.

Gjesdal, F. Stewardship Accounting: Controlling Informational Externalities. Unpublished Dissertation, Stanford U niversity, 1978.

Grossman, S. J., and O. D. H art. "An A nalysis of the Principal-A gent Problem." E conometrica, (1983): 7-46.

Harris, M., and R. Townsend, "Allocation M echanisms, A symmetric Information and the 'Revelation Principle'." in Issues in Contemporary Microeconomics and Welfare ed. by George Feiwel. A lbany, New Y ork: SUNY press, 1981.

Holmström, B. and P. M ilgrom. "A ggregation and Linearity in the Provision of Intertemporal Incentives." Econometrica (1987): 303-328.

Holmström, B. "M oral Hazard A nd Observability." Bell J ournal of E conomics, (1979): 74-91.

Horngren, C. T. "How Should We Interpret the Realization Principle?" Accounting Review (A pril, 1965): 325-333.

Johnson, L. T., and R. K. Storey, Recognition in Financial Statements: U nderlying Concepts and Practical Conventions. Stamford, CT: FA SB, 1982

Kim, S. K., "Efficiency of an Information System in an A gency M odel," E conometrica, (January 1995): 89-102.

Lambert, R. A. "Long-term Contracts and M oral Hazard." The Bell J ournal of Economics, (A utumn 1983): $441-452$.

L ambert, R., and D. L arcker, "An A nalysis of the $U$ se of A ccounting and $M$ arket $M$ easures of Performance in Executive Compensation Contracts, " J ournal of Accounting Research, (1987 supp): 85125.

Lee, T. A. Income and Value Measurement: Theory and Practice. Great Britain: Nelson, 1974.

Lev, B., "On the U sefulness of Earnings and Earnings Research: L essons and Directions from Two Decades of Empirical Research." J ournal of Accounting Research (1989 supp). 
Malcomson, J., and F. Spinnewyn, "The Multiperiod Principal-A gent Problem." Review of Economic Studies, (1988): 391-408

M elumad, N., and S. Reichelstein, "Centralization V ersus D elegation and the V alue of Communication." Journal of Accounting Research, (1987 supp).

Myers, J. H., "The Critical Event and Recognition of Net Profit." Accounting Review, (1959): 528-32.

Myerson, R., "Incentive Compatibility and the Bargaining Problem." Econometrica, (J an 1979): 61-73.

Paton, W. A. Accounting Theory. New Y ork, NY: Ronald Press, 1922. Republished by Accounting Studies Press, Ltd., 1962.

Penno, M., "A symmetry of Pre-Decision Information and M anagerial A ccounting," J ournal of Accounting Research, (1984): 177.

Penno, M ., [1990a] "A ccounting Systems, Participation in Budgeting, and Performance Evaluation," Accounting Review, (1990): 303-314.

Penno, M ., [1990b] “A uditing for Performance Evaluation," Accounting Review, (1990): 520-536.

Radner, R., "Repeated Principal-A gent Games with Discounting." Econometrica, (1985): 1173.

Rogerson, W., "Repeated M oral H azard," Econometrica, (1985): 69.

Sloan, R., "Accounting Earnings and Top Executive Compensation." J ournal of Accounting and Economics (1993): $55-100$

Sprouse, R. T. "Observations Concerning the Realization Concept." Accounting Review (A pril, 1965): 522-526.

Sundem, G., R.E. Dukes, and J. A. Elliott, The Value of Information and Audits. Coopers \& Lybrand M onograph. Coopers \& Lybrand L. L. P. Jersey City, NJ, 1997.

Takayama, A., Mathematical Economics. Hinsdal, IL: The Dryden Press, 1974. 


\section{APPENDIX: PROOFS}

\section{Proof of Proposition 1:}

We begin with the basic model:

$$
\begin{aligned}
& C^{*} / \underset{I(x)}{\operatorname{minimum}} E[I(x) \mid H, " H]=E_{x} P(x \mid H H) I(x) \\
& \text { Subject to } E[U(I(x) ; @ H, " H] \$ \underline{U} \\
& E\left[U ( I ( x ) ; @ H , " { } ^ { H } ] \$ E \left[U\left(I(x) ; @ a_{1}, "\right] \text { ú } a_{1}, "\right.\right.
\end{aligned}
$$

with $a_{1} O\{H, L\}$ and ": $\{G, B\} 6\{H, L\}$, the agent has eight possible strategies:

\begin{tabular}{llll} 
Strategy & $\mathrm{a}_{1}$ & \multicolumn{2}{c}{ " } \\
& & & " (B) \\
(i) & $\mathrm{H}$ & $\mathrm{H}$ & $\mathrm{H}$ \\
(ii) & $\mathrm{H}$ & $\mathrm{L}$ & $\mathrm{H}$ \\
(iii) & $\mathrm{H}$ & $\mathrm{H}$ & $\mathrm{L}$ \\
(iv) & $\mathrm{H}$ & $\mathrm{L}$ & $\mathrm{L}$ \\
(v) & $\mathrm{L}$ & $\mathrm{H}$ & $\mathrm{H}$ \\
(vi) & $\mathrm{L}$ & $\mathrm{L}$ & $\mathrm{H}$ \\
(vii) & $\mathrm{L}$ & $\mathrm{H}$ & $\mathrm{L}$ \\
(viii) & $\mathrm{L}$ & $\mathrm{L}$ & $\mathrm{L}$
\end{tabular}

In general, there are seven IC constraints in the basic model (e.g., strategy (i) is preferred to (ii), (iii)). We label the seven IC constraints by their off-equilibrium strategy numbers, (ii) through (viii). Given [A 1] and [A 2], we can collapse the seven IC constraints into two IC constraints.

To proceed, constraint (ii) requires:

$P(G \mid H) E[U \mid G, H H]+P(B \mid H) E[U \mid B, H H] \$ P(G \mid H) E[U \mid G, H L]+P(B \mid H) E[U \mid B, H H]$

Canceling common terms, the constraint simplifies to:

$E[U \mid G, H H] \$ E[U \mid G, H L]$

[A 1] implies $P\left(x, z_{2} \mid z_{1}, a_{1}, a_{2}\right)=P\left(x \mid a_{1}, a_{2}\right) P\left(z_{2} \mid a_{2}\right)$ for all $z_{1}, z_{2}$, and $t_{1}, a_{2}$. Therefore, constraint (ii) reduces to:

$E[U \mid H H] \$ E[U \mid H L]$ 
where $E\left[U \mid a_{1}, a_{2}\right] / G_{x} P\left(x \mid a_{1}, a_{2}\right) U\left(I(x) ; a_{1}, a_{2}\right)$

Similarly, by [A 1], constraints (iii) and (iv) are identical to (AI-1). Thus, constraints (ii), (iii), and (iv) can be replaced by (AI-1), which we rename the second-period IC constraint.

Similarly, [A 1] simplifies constraints (v) through (viii) to these four inequalities:

constraint (v): $\quad \quad E[U \mid H H] \$ E[U \mid L H]$

constraint (vi): $\quad E[U \mid H H] \$ P(G \mid L) E[U \mid L L]+P(B \mid L) E[U \mid L H]$

constraint (vii): $E[U \mid H H] \$ P(G \mid L) E[U \mid L H]+P(B \mid L) E[U \mid L L]$

constraint (viii): $\quad E[U \mid H H] \$ E[U \mid L L]$

Clearly constraints (v) and (viii) imply constraints (vi) and (vii). Given [A2], the CDFC assumption, it is easy to verify constraint (viii) does not bind.

We rename constraint $(v)$ the first-period IC constraint. Thus far, all but the following three constraints in the basic model have been eliminated: (1) the IR constraint, (2) the first-period IC constraint (constraint (v)), and (3) the second-period IC constraint (inequality (AI-1)).

Let : , $8_{1}$, and $8_{2}$ be the non-negative $L$ agrange multipliers associated with these three constraints respectively. We set up the following L agrangian:

$$
\begin{aligned}
\tilde{a}= & E[I(x) \mid H, " H] !:(E[U \mid H H] ! \underline{U}) ! 8_{1}(E[U \mid H H] ! E[U \mid L H]) \\
& \left.! 8_{2}(E[U \mid H H)]-E[U \mid H L]\right)
\end{aligned}
$$

From the first-order conditions, it is easy to verify that:

(i) : > 0 (Holmström and M ilgrom [1987]),

(ii) if $P(x=1 \mid L H)>P(x=1 \mid H L)$, then $8_{1}>0$ and $8_{2}=0$ (because $t, H$, dominates $H, L$, in the sense of first order stochastic dominance and $\mathrm{I}(\mathrm{X}=1)>\mathrm{I}(\mathrm{X}=0)$ in equilibrium), and

(iii) if $P(x=1 \mid L H)<P(x=1 \mid H L)$, then $8_{2}>0$ and $8_{1}=0$.

Now we analyze the usefulness of $R_{t}$. Under $R_{2}, y_{2}$ is just an ex post monitor. From Holmström [1979] and Grossman and Hart [1983] where there is only one binding IC constraint, we know a monitor, say $\mathrm{y}_{2}$, is useful if the likelihood ratio associated with the constraint is a function of $y_{2}$. This is the case 
here because when $P(x=1 \mid L H)>P(x=1 \mid H L), z_{1}$ is incentive informative about $a_{1}$ and $y_{2}$ is a garbling, but not independent, of $z_{1}$. A parallel argument applies to the case when $P(x=1 \mid L H)<P(x=1 \mid H L)$.

Now consider $R_{1}$. First, suppose $P(x=1 \mid L H)<P(x=1 \mid H L)$, we claim $R_{1}$ is useless. Under $R_{1}$, the agent's second-period policy is a mapping " : ZXY $6 \mathrm{~A}$. There are now 16 possible " mappings. M ixed with $\mathrm{a}_{1}$, there are 32 possible strategies. To avoid repetition, we replace the 15 IC constraints involving $H$, , , ("Ö"H) with the following four constraints:

$E\left[U \mid z_{1}, y_{1}, H H\right] \$ E\left[U \mid z_{1}, y_{1}, H L\right]$ ú $z_{1}, y_{1}$

These four constraints imply that the agent, having chosen $\mathrm{a}_{1}=\mathrm{H}$, will choose $\mathrm{a}_{2}=\mathrm{H}$ for all possible realizations of $z_{1}$ and $y_{1}$. If (AI-5) is satisfied, the 15 IC constraints that involve $+\mathrm{H}$, " , (" Ö" H) are also satisfied. ${ }^{39}$

[A 1] and the fact $y_{1}$ is a garbling of $z_{1}$ imply $P\left(x \mid z_{1}, y_{1}, a_{1}, a_{2}\right)=P\left(x \mid a_{1}, a_{2}\right)$, so (A I-5) reduces to the following two constraints:

$\left.E\left[U \mid y_{1}, H H\right] \$ E\left[U \mid y_{1}, H L\right)\right]$ ú $y_{1}$

where $E\left[U \mid y_{1}, a_{1}, a_{2}\right] / G_{x} P\left(x \mid a_{1}, a_{2}\right) U\left(I\left(x, y_{1}\right) ; A\right.$

We solve the optimization problem with only the two constraints in (AI-6) and the IR constraint, (ignoring the other $16 \mathrm{IC}$ constraints involving $t$, ", for the moment). We obtain the following firstorder conditions:

$\frac{-1}{\operatorname{rV}\left(I\left(x, y_{1}\right)\right) k^{2}}=\mu+\lambda\left(y_{1}\right)\left(1-\frac{P(x \mid H L)}{k P(x \mid H H)}\right) \forall x, y_{1}$

39 To see this, write the 15 constraints as: $E\left[U(A) H,{ }^{H}{ }^{H}\right] \$ E[U(A) H, ~ "] \quad$ ú "Ö" ${ }^{H}$. But $E[U(A) H$, $\left.{ }^{{ }^{H}}\right]=G_{Z, Y} E\left[U \mid z_{1}, y_{1}, H H\right]$ and $E\left[U(A \mid H, "]=G_{Z, Y} E\left[U \mid z_{1}, y_{1}, H, "\left(z_{1}\right)\right]\right.$. Given (AI-5), each of the four terms in $E\left[U(A) H, "{ }^{H}\right]$ is greater than or equal to its counterpart in $E[U(A) H, "]$. 
From here it is clearly that $R_{1}$ is useless if $P(x=1 \mid L H)<P(x=1 \mid H L)$, as strict use would needlessly impose risk on the agent. If the principal does not use $y_{1}$, the omitted IC constraints are clearly satisfied, $\mathrm{R}_{1}$ is indeed useless.

Now, suppose $P(x=1 \mid L H)>P(x=1 \mid H L)$, but let $I^{*}\left(x, y_{1}\right)=I^{*}(x)$, where $I^{*}(x)$ is the optimal contract from the basic model. We show this solution violates the optimality conditions in the expanded program. With this supposed solution, the IR constraint binds, only one IC constraint is binding by complementary slackness. The binding IC constraint must involve $t,{ }^{~}{ }^{H}$, A All other 30 off-equilibrium strategies result in input sequence $H, L$, or $t, L$, with non-zero probability and are, therefore, dominated by $t, " H$, under incentive scheme $I^{*}(x)$. (CDFC is used here.) The first-order conditions evaluated using the supposed solution is:

$\frac{-1}{r V\left(I^{*}\left(x, y_{1}\right)\right) k^{2}}=\mu+\lambda\left(L, \alpha^{H}\right)\left(1-\frac{P(x \mid L H) \sum_{z} P\left(y_{1} \mid z_{1}\right) P\left(z_{1} \mid a_{1}=L\right)}{k P(x \mid H H) \sum_{z} P\left(y_{1} \mid z_{1}\right) P\left(z_{1} \mid a_{1}=H\right)}\right)$ ú $x, y_{1}$

The right-hand-side of (AI-8) is a non-trivial function of $y_{1}$ because (i) $z_{1}$ is incentive informative about $a_{1}$ and (ii) $y_{1}$ is a garbling but not independent of $z_{1}$. However, the left-hand-side of (AI-8) is not, under the supposed solution.

\section{Proof of Observation 1:}

When only $\mathrm{x}$ is contractible, the design program with communication is as follows:

$$
C(m) / \underset{I(A}{\operatorname{minimum}} E\left[I\left(x, m\left(z_{1}\right)\right) \mid H, m^{\top},{ }^{H}\right]
$$

Subject to $E\left[U(I) @ \Theta H, m^{\top}, " H\right] \$ \underline{U}$

$E\left[U\left(I\left(@ \bigotimes H, m^{\top}, " H\right] \$ E\left[U\left(I\left(@ \bigotimes a_{1}, m, "\right]\right.\right.\right.\right.$ ú $a_{1}, m, " ~ "$

The agent's strategy for the entire game is represented by $t_{1}, m$, ", There are four possible self-reporting policies, denoted $\mathrm{m}^{\top}, \mathrm{m}^{\mathrm{GG}}, \mathrm{m}^{\mathrm{BB}}$, and $\mathrm{m}^{\mathrm{BG}}$, where $\mathrm{m}^{\top}$ is the truth-telling policy, $\mathrm{m}^{\mathrm{GG}}$ (resp. $\mathrm{m}^{\mathrm{B}}$ ) is the policy that always reports good news (resp. bad news), and $\mathrm{m}^{\mathrm{BG}}$ is the policy under which the 
agent always lies. Recall there are four second-period input policies ("). Therefore, for the entire game, the agent has 32 possible strategies. The preferred strategy is $H, m^{\top}, " H$,. The design program has 31 IC constraints and one IR constraint.

We use a variation argument to prove communication is strictly useful. $L$ et $\mathbf{H}_{1}{ }^{*}, \mathrm{v}_{0}{ }^{*}$, be the optimal payment scheme, in utility terms, for the mechanism design program without communication. We construct a trial solution $v_{m(A x}$ in utility terms, to the program with communication: $v_{m(A x}=v_{x}^{*} u_{x}$, $m(A O Z$. Clearly, the solution is feasible. Since $P(x=1 \mid L H)>P(x=1 \mid H L)$, only 7 of $31 I C$ constraints are satisfied with equality, which correspond to the following off-equilibrium strategies:

$\begin{array}{lll}\mathrm{a}_{1} & \mathrm{~m} & \text { " } \\ \mathrm{H} & \mathrm{m}^{\mathrm{GG}} & \text { "H } \\ \mathrm{H} & \mathrm{m}^{\mathrm{BB}} & \text { "H } \\ \mathrm{H} & \mathrm{m}^{\mathrm{BG}} & \text { "H } \\ \mathrm{L} & \mathrm{m}^{\top} & \text { "H } \\ \mathrm{L} & \mathrm{m}^{\mathrm{GG}} & \text { "H } \\ \mathrm{L} & \mathrm{m}^{\mathrm{BB}} & \text { "H } \\ \mathrm{L} & \mathrm{m}^{\mathrm{BG}} & \text { "H }\end{array}$

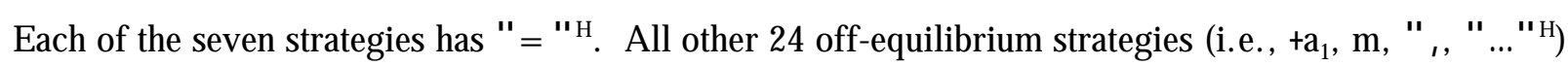
result in input sequence $H, L$, or $t, L$, with non-zero probability and are, therefore, dominated by $t$, $m, " H$, or $H, m, "{ }^{H}$, under the trial solution $v_{m}(A x$.

A long with the IR constraints, we have the following eight constraints satisfied with equality:

$$
\begin{aligned}
& \left.E[U] />{ }_{G} V_{G 1}+\ngtr 1 !{ }_{G}\right) v_{G 0}+\left(1 ! \ngtr_{\cdot}{ }_{B} v_{B 1}+\left(1 ! \ngtr\left(1 !{ }_{B}\right) v_{B 0} ! \underline{U} \$ 0\right.\right. \\
& E[U] !\left[. v_{G 1}+(1 ! .) v_{G 0}\right] \$ 0 \\
& E[U] !\left[. v_{B 1}+(1 ! .) v_{B 0}\right] \$ 0 \\
& E[U] !\left[\gtrless_{{ }_{G}} V_{B 1}+\ngtr 1 !{ }_{G}\right) v_{B 0}+\left(1 ! \ngtr_{B_{B}} V_{G 1}+\left(1 ! \ngtr\left(1 !{ }_{B}\right) v_{G O}\right] \$ 0\right. \\
& E[U] !\left[>N k v_{G 1}+\ngtr 1 \text { ! . Nkkv } v_{G 0}+\left(1 ! \ngtr . N k v_{B 1}+\left(1 ! \ngtr\left(1 ! . N k v_{B 0}\right] \$ 0\right.\right.\right. \\
& E[U] !\left[. \mathrm{Nkv}_{\mathrm{G} 1}+\left(1 ! . \mathrm{Nkv}_{\mathrm{GO}}\right] \$ 0\right. \\
& \mathrm{E}[\mathrm{U}] \text { ! [. } . \mathrm{Nkv}_{\mathrm{B} 1}+\left(1 ! . \mathrm{N} / \mathrm{kv} \mathrm{B}_{\mathrm{B}}\right] \$ 0
\end{aligned}
$$


$E[U] !\left[>N v_{B 1}+\ngtr 1\right.$ ! . NNkv $v_{B 0}+\left(1 ! \ngtr . N v_{G 1}+\left(1 ! \ngtr\left(1 ! . N k v_{G 0}\right] \$ 0\right.\right.$

where:

$\ngtr P\left(z_{1}=G\right) ; \cdot{ }_{G} / P\left(x=1 \mid z_{1}=G, H H\right) ; \cdot{ }_{B} / P\left(x=1 \mid z_{1}=B, H H\right), . N P(x=1 \mid L H), . / P(x=1 \mid H H)=\gtrless_{G}$

$+\left(1 !{\psi_{B}}_{B}\right.$ and $._{G}>.>_{{ }_{B}}>. N$

Rewriting the principal's objective function, in utility terms, we have:

$E\left[I\left(x, m(A) \mid H, m^{\top},{ }^{H}\right]=>{ }_{G} V ! 1\left(V_{G 1}\right)+\ngtr 1 !{ }_{G}\right) V ! 1\left(V_{G 0}\right)+\left(1 ! \ngtr_{\cdot} V ! 1\left(V_{B 1}\right)\right.$

$$
+\left(1 ! \ngtr\left(1 !{ }_{B}\right) V ! 1\left(V_{B}\right)\right.
$$

Totally differentiating (IR), $\left(T_{G G}\right),\left(I C_{B B}\right)$, and the principal's objective function at the trial solution, we have:

)$\left.I R=>_{G} d_{V_{G 1}}+\ngtr 1 !{ }_{G}\right) d v_{G O}+\left(1 ! \ngtr_{B_{B}} d v_{B 1}+\left(1 ! \ngtr\left(1 ! \cdot{ }_{B}\right) d v_{B O}\right.\right.$

) $\left.\mathrm{TT}_{\mathrm{GG}}=\right)$ IR ! $\cdot \mathrm{dv}_{\mathrm{G} 1} !(1 ! \cdot) \mathrm{dv}_{G 0}$

)$\left.I C_{B B}=\right) I R ! . N \forall d v_{B 1} !\left(1 ! . N \mid k d v_{B O}\right.$

) $E\left[I(A]=\mathbb{W} ! 1 / \mathbb{N}\left(v_{1}^{*}\right)\left[>_{G} d v_{G 1}+\left(1 ! \ngtr_{B} d v_{B 1}\right]+\mathbb{W} ! 1 / \mathbb{N}\left(v_{0}^{*}\right)\left[\ngtr 1 !{ }_{G}\right) d v_{G 0}\right.\right.$

$+\left(1 ! \nsucc\left(1 !{ }_{B}\right) d v_{B O}\right]$

For a fixed $d v_{G 1}>0$, choose $\mathrm{dv}_{G 0}, d v_{B 1}$, and $d v_{B 0}$ so that ) IR $\left.=0,\right) I C_{B B}=0$, and $) T_{G G}=0$. Therefore we have system of three linear equations with three unknowns. Solving the system ${ }^{40}$, we have: $\operatorname{sign}[) E[\mid(A)]=\operatorname{sign}(T)=\operatorname{sign}\left[._{B}\left(1-. N\left(1-{ }_{G}\right)-. N_{G}(1-).\left(1-{ }_{B}\right)\right]\right.$

Therefore, the expected payment is reduced, i.e., ) $E[I(\mathbb{A}]<0$, if

$$
\frac{\zeta\left(1-\zeta^{\prime}\right)}{\zeta^{\prime}(1-\zeta)}<\frac{\zeta_{G}\left(1-\zeta_{B}\right)}{\zeta_{B}\left(1-\zeta_{G}\right)}
$$

With $d v_{G 1}, d v_{G 0}, d v_{B 1}$, and $d v_{B 0}$ chosen in such a way, we can readily verify that constraints $\left(T_{B B}\right),\left(T_{B G}\right),\left(I C_{T}\right),\left(I C_{G G}\right)$ and $\left(I C_{B G}\right)$ are satisfied.

40 One can readily verify the determinant of the coefficient matrix is not zero, so the solution to the system of three linear equations exists. 


\section{Proof of Proposition 2:}

The design program with recognition and communication is as follows:

$$
C\left(R_{t}, m\right) / \underset{I(A}{\operatorname{minimum}} E\left[I\left(x, y_{t}, m\left(z_{1}\right)\right) \mid H, m^{\top},{ }^{H}\right]
$$

Subject to $E\left[U\left(I\left(@ @ H, m^{\top},{ }^{H}\right]\right.\right.$ \$ $\underline{U}$

$$
\text { E[U(I)@@H, m , "H] \$E[U(I(@@ }
$$

U nder $R_{2}$, the agent has 32 strategies. Let $8\left(a_{1}, m\right.$, ") denote the non-negative $L$ agrange

multipliers and let : denote the multiplier associated with the IR constraint. The first order condition can be written as:

$\frac{-1}{\mathrm{rV}\left(\mathrm{I}\left(\mathrm{x}, \mathrm{y}_{2}, \mathrm{~m}(.)\right) \mathrm{k}^{2}\right.}=\mu+\sum_{\left\langle\mathrm{a}_{1}, \mathrm{~m}, \alpha\right\rangle \neq\left\langle\mathrm{H}, \mathrm{m}^{\mathrm{T}}, \mathrm{\alpha}^{\mathrm{H}}\right\rangle} \lambda\left(\mathrm{a}_{1}, \mathrm{~m}, \alpha\right) \Lambda\left(\mathrm{a}_{1}, \mathrm{~m}, \alpha\right)$

where $7\left(a_{1}, m, "\right)$ will be specified in the following. Specifically, the first order condition with respect to $I\left(x, y_{2}, G\right)$ can be expanded to:

$$
\begin{aligned}
\frac{-1}{\mathrm{rV}\left(\mathrm{I}\left(\mathrm{x}, \mathrm{y}_{2}, \mathrm{G}\right) \mathrm{k}^{2}\right.} & =\mu+\sum_{\left.\left\langle\mathrm{a}_{1}, \alpha\right) \neq \mathrm{H}, \alpha^{\mathrm{H}}\right\rangle} \lambda\left(\mathrm{a}_{1}, \mathrm{~m}^{\mathrm{T}}, \alpha\right)\left(1-\kappa\left(\mathrm{a}_{1}, \alpha(\mathrm{G})\right) \frac{\mathrm{P}\left(\mathrm{x} \mid \mathrm{z}_{1}=\mathrm{G}, \mathrm{a}_{1}, \alpha(\mathrm{G})\right)}{\mathrm{P}\left(\mathrm{x} \mid \mathrm{z}_{1}=\mathrm{G}, \mathrm{HH}\right)}\right)+\sum_{\mathrm{a}_{1}, \alpha} \lambda\left(\mathrm{a}_{1}, \mathrm{~m}^{\mathrm{BB}}, \alpha\right) \\
& +\sum_{\mathrm{a}_{1}, \alpha} \lambda\left(\mathrm{a}_{1}, \mathrm{~m}^{\mathrm{GG}}, \alpha\right)\left(1-\kappa\left(\mathrm{a}_{1}, \alpha(\mathrm{G})\right) \frac{\mathrm{P}\left(\mathrm{x} \mid \mathrm{z}_{1}=\mathrm{G}, \mathrm{a}_{1}, \alpha(\mathrm{G})\right)}{\mathrm{P}\left(\mathrm{x} \mid \mathrm{z}_{1}=\mathrm{G}, \mathrm{HH}\right)}-\phi_{2} \mathrm{~K}\left(\mathrm{a}_{1}, \alpha(\mathrm{B})\right) \frac{(1-\gamma) \mathrm{P}\left(\mathrm{x} \mid \mathrm{z}_{1}=\mathrm{B}, \mathrm{a}_{1}, \alpha(\mathrm{B})\right)}{\gamma \mathrm{P}\left(\mathrm{x} \mid \mathrm{z}_{1}=\mathrm{G}, \mathrm{HH}\right)}\right) \\
& +\sum_{\mathrm{a}_{1}, \alpha} \lambda\left(\mathrm{a}_{1}, \mathrm{~m}^{\mathrm{BG}}, \alpha\right)\left(1-\phi_{2} \mathrm{~K}\left(\mathrm{a}_{1}, \alpha(\mathrm{B})\right) \frac{(1-\gamma) \mathrm{P}\left(\mathrm{x} \mid \mathrm{z}_{1}=\mathrm{B}, \mathrm{a}_{1}, \alpha(\mathrm{B})\right)}{\gamma \mathrm{P}\left(\mathrm{x} \mid \mathrm{z}_{1}=\mathrm{G}, \mathrm{HH}\right)}\right)
\end{aligned}
$$

where $m^{G G}, m^{B B}$, and $m^{B G}$ are defined as in the proof of Observation $1, N_{2}=P\left(y_{2} \mid z_{1}=B\right) / P\left(y_{2} \mid z_{1}=G\right)$, and $6\left(a_{1}, a_{2}\right)=\exp \left(r\left(c\left(a_{1}\right)+c\left(a_{2}\right)-2 c(H)\right)\right.$. Similarly, the first order condition with respect to $I\left(x, y_{2}, B\right)$ can be expanded to: 


$$
\begin{aligned}
\frac{-1}{\mathrm{rV}\left(\mathrm{I}\left(\mathrm{x}, \mathrm{y}_{2}, \mathrm{~B}\right) \mathrm{k}^{2}\right.} & =\mu+\sum_{\left\langle\mathrm{a}_{1}, \alpha\right) \neq\left\langle\mathrm{H}, \alpha^{\mathrm{H}}\right\rangle} \lambda\left(\mathrm{a}_{1}, \mathrm{~m}^{\mathrm{T}}, \alpha\right)\left(1-\kappa\left(\mathrm{a}_{1}, \alpha(\mathrm{B})\right) \frac{\mathrm{P}\left(\mathrm{x} \mid \mathrm{z}_{1}=\mathrm{B}, \mathrm{a}_{1}, \alpha(\mathrm{B})\right)}{\mathrm{P}\left(\mathrm{x} \mid \mathrm{z}_{1}=\mathrm{B}, \mathrm{HH}\right)}\right)+\sum_{\mathrm{a}_{1}, \alpha} \lambda\left(\mathrm{a}_{1}, \mathrm{~m}^{\mathrm{GG}}, \alpha\right) \\
& +\sum_{\mathrm{a}_{1}, \alpha} \lambda\left(\mathrm{a}_{1}, \mathrm{~m}^{\mathrm{BB}}, \alpha\right)\left(1-\kappa\left(\mathrm{a}_{1}, \alpha(\mathrm{B})\right) \frac{\mathrm{P}\left(\mathrm{x} \mid \mathrm{z}_{1}=\mathrm{B}, \mathrm{a}_{1}, \alpha(\mathrm{B})\right)}{\mathrm{P}\left(\mathrm{x} \mid \mathrm{z}_{1}=\mathrm{B}, \mathrm{HH}\right)}-\phi_{2}{ }^{-1} \kappa\left(\mathrm{a}_{1}, \alpha(\mathrm{G})\right) \frac{\gamma \mathrm{P}\left(\mathrm{x} \mid \mathrm{z}_{1}=\mathrm{G}, \mathrm{a}_{1}, \alpha(\mathrm{G})\right)}{(1-\gamma) \mathrm{P}\left(\mathrm{x} \mid \mathrm{z}_{1}=\mathrm{B}, \mathrm{HH}\right)}\right) \\
& +\sum_{\mathrm{a}_{1}, \alpha} \lambda\left(\mathrm{a}_{1}, \mathrm{~m}^{\mathrm{BG}}, \alpha\right)\left(1-\phi_{2}{ }^{-1} \kappa\left(\mathrm{a}_{1}, \alpha(\mathrm{G})\right) \frac{\gamma \mathrm{P}\left(\mathrm{x} \mid \mathrm{z}_{1}=\mathrm{G}, \mathrm{a}_{1}, \alpha(\mathrm{G})\right)}{(1-\gamma) \mathrm{P}\left(\mathrm{x} \mid \mathrm{z}_{1}=\mathrm{B}, \mathrm{HH}\right)}\right)
\end{aligned}
$$

We know $\mathrm{N}_{2}$ is a non-trivial function of $\mathrm{y}_{2}$ because $\mathrm{y}_{2}$ is not independent of $z_{1}$. If the principal strictly prefers communication with no recognition, then at least one truth-telling constraint is binding, i.e., at least one of the multipliers $8\left(a_{1}, m^{G G}, "\right), 8\left(a_{1}, m^{B B}, "\right)$, or $8\left(a_{1}, m^{B G}, "\right)$ is positive. Thus, we have the right-hand-side of (AII-9) as a non-trivial function of $y_{2}$ (if some $8\left(a_{1}, m^{G G}, "\right.$ ), or $8\left(a_{1}, m^{B G}, "\right.$ ) is nonzero), or we have the right-hand-side of (AII-10) as a non-trivial function of $y_{2}$ (if some $8\left(a_{1}, m^{B B}, "\right.$ ), or the $8\left(a_{1}, m^{B G}, "\right)$ is non-zero), or both ${ }^{41}$. Therefore, $y_{2}$ is useful for contracting.

Now consider $R_{1}$. First consider the program with no recognition. Let $S$ denote the set of offequilibrium strategies in this program, strategies denoted $t_{1}, m, "$, . In the program with $R_{1}$, the agent chooses among strategies $\underline{\underline{t}}_{1}, \underline{\mathrm{m}},{ }^{\prime}$,. (W e use an underline "_" to denote the elements of strategies in the program with $R_{1}$ to avoid confusion.) Here, " $Z$ : $Z \times Y 6 \mathrm{~A}$. There are sixteen possible " mappings. Mixed with $\underline{a}_{1} O\{\mathrm{H}, \mathrm{L}\}$ and $\underline{m} O\left\{\mathrm{~m}^{\top}, \mathrm{m}^{\mathrm{GG}}, \mathrm{m}^{\mathrm{BB}}, \mathrm{m}^{\mathrm{BG}}\right\}$, the agent has one hundred twenty-eight strategies.

In this expanded program, we construct an off-equilibrium strategies set, denoted $\underline{\mathbf{S}}$, in the following way. For each strategy $\mathfrak{b}_{1}, \mathrm{~m}, \mathrm{~N}, \mathrm{OS}$, find the strategy in the program with $\mathrm{R}_{1}$ such that $\underline{a}_{1}=$ $a_{1}, \underline{m}=m$, and $\left.\underline{-}_{1}, y_{1}\right)="\left(z_{1}\right)$ for all $y_{1}$.

By construction, the agent's second-period input is not a function of $y_{1}$ for strategies in $\underline{S}$. We write " $\left(z_{1}, \sigma\right.$ to reflect this fact. Further, we partition $\underline{S}$ into four subsets: those that use $\mathrm{m}^{\top}, \underline{\mathrm{S}}_{\top}$; those that use $\mathrm{m}^{\mathrm{GG}}, \underline{\mathrm{S}}_{\mathrm{GG}}$, etc.

41 Note that in the right-hand-sides of both (AII-9) and (All-10), the coefficients on $\mathrm{N}_{2}^{-1}$ are either negative or zero. 
Now we take the optimal solution in the program with no recognition to construct a trial solution to the program with $R_{1}$ by setting $I\left(x, y_{2}, m(A)=I^{*}(x, m(A)\right.$. If all constraints involving strategies not in $\underline{\mathrm{S}}$ are redundant, (which will be proved to be true later,) we can evaluate the first order conditions in the program with $\mathrm{R}_{1}$ at the trial solution as follows:

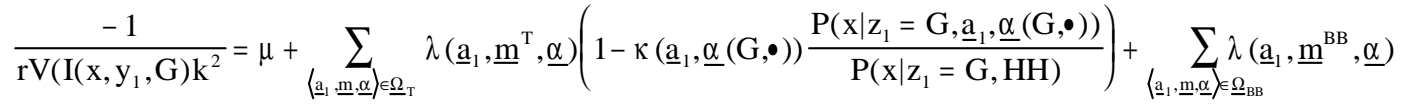

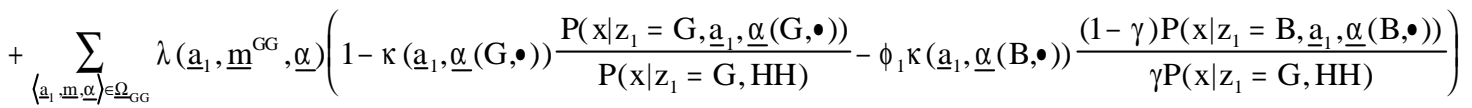

$$
\begin{aligned}
& +\sum_{\langle\underline{\mathrm{a}}, \underline{\underline{m}, \underline{\alpha}}) \in \underline{\Omega}_{\mathrm{BG}}} \lambda\left(\underline{\mathrm{a}}_{1}, \underline{\mathrm{m}}^{\mathrm{BG}}, \underline{\alpha}\right)\left(1-\phi_{1} \kappa\left(\underline{\mathrm{a}}_{1}, \underline{\alpha}(\mathrm{B}, \bullet)\right) \frac{(1-\gamma) \mathrm{P}\left(\mathrm{x} \mid \mathrm{z}_{1}=\mathrm{B}, \underline{\mathrm{a}}_{1}, \underline{\alpha}(\mathrm{B}, \bullet)\right)}{\gamma \mathrm{P}\left(\mathrm{x} \mid \mathrm{z}_{1}=\mathrm{G}, \mathrm{HH}\right)}\right)
\end{aligned}
$$

and

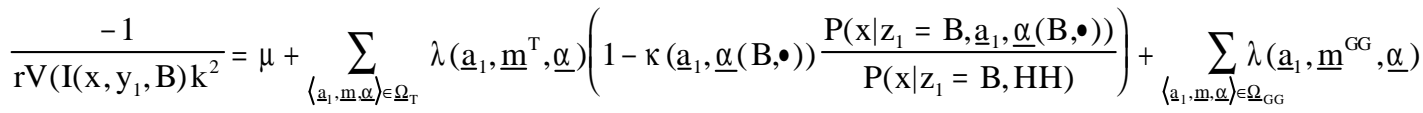

$$
\begin{aligned}
& +\sum_{\underline{\underline{a}}, \underline{\mathrm{m}}, \underline{\alpha}) \in \underline{\Omega}_{\mathrm{BB}}} \lambda\left(\underline{\mathrm{a}}_{1}, \underline{\mathrm{m}}^{\mathrm{BB}}, \underline{\alpha}\right)\left(1-\kappa\left(\underline{\mathrm{a}}_{1}, \underline{\alpha}(\mathrm{B}, \bullet)\right) \frac{\mathrm{P}\left(\mathrm{x} \mid \mathrm{z}_{1}=\mathrm{B}, \underline{\mathrm{a}}_{1}, \underline{\alpha}(\mathrm{B}, \bullet)\right)}{\mathrm{P}\left(\mathrm{x} \mid \mathrm{z}_{1}=\mathrm{B}, \mathrm{HH}\right)}-\phi_{1}^{-1} \kappa\left(\underline{\mathrm{a}}_{1}, \underline{\alpha}(\mathrm{G}, \bullet)\right) \frac{\gamma \mathrm{P}\left(\mathrm{x} \mid \mathrm{z}_{1}=\mathrm{G}, \underline{\mathrm{a}}_{1}, \underline{\alpha}(\mathrm{G}, \bullet)\right)}{(1-\gamma) \mathrm{P}\left(\mathrm{x} \mid \mathrm{z}_{1}=\mathrm{B}, \mathrm{HH}\right)}\right) \\
& +\sum_{\langle\underline{\underline{a}},, \underline{\underline{m}, \underline{\alpha}})_{\underline{\underline{\Omega}}} \underline{\underline{B G}}_{\mathrm{BG}}} \lambda\left(\underline{\mathrm{a}}_{1}, \underline{\mathrm{m}}^{\mathrm{BG}}, \underline{\alpha}\right)\left(1-\phi_{1}{ }^{-1} \kappa\left(\underline{\mathrm{a}}_{1}, \underline{\alpha}(\mathrm{G}, \bullet)\right) \frac{\gamma \mathrm{P}\left(\mathrm{x} \mid \mathrm{z}_{1}=\mathrm{G}, \underline{\mathrm{a}}_{1}, \underline{\alpha}(\mathrm{G}, \bullet)\right)}{(1-\gamma) \mathrm{P}\left(\mathrm{x} \mid \mathrm{z}_{1}=\mathrm{B}, \mathrm{HH}\right)}\right)
\end{aligned}
$$

where $N_{1}=P\left(y_{1} \mid z_{1}=B\right) / P\left(y_{1} \mid z_{1}=G\right)$. We know $N_{1}$ is a non-trivial function of $y_{1}$ because $y_{1}$ is not independent of $z_{1}$. If the principal strictly prefers communication with no recognition, then at least one truth-telling constraint is binding, i.e., at least one of the multipliers $8\left(\underline{a}_{1}, \mathrm{~m}^{\mathrm{GG}}, \underline{\prime \prime}\right), 8\left(\underline{a}_{1}, \mathrm{~m}^{\mathrm{BB}}, \underline{\prime}\right)$, or $8\left(\underline{a}_{1}, \mathrm{~m}^{\mathrm{BG}}\right.$, " $)$ is positive. So we have the right-hand-side of (All-11) as a non-trivial function of $\mathrm{y}_{1}$ or we have the right-hand-side of (AII-12) as a non-trivial function of $\mathrm{y}_{1}$, or both. Therefore, $\mathrm{y}_{1}$ is useful.

Now we prove that under the trial payment scheme, the constraints involving strategies not in $\underline{\mathrm{S}}$ are, in fact, redundant. Let $\underline{\underline{\mathrm{S}}}$ denote the set of all such strategies. Partition $\underline{\underline{\mathrm{S}}}$ into two subsets denoted $\underline{\mathrm{S}}^{1}$ and $\underline{\mathrm{S}}^{2} . \underline{\mathrm{S}}^{1}$ is the set of strategies in which the agent's second-period input is a function of $\mathrm{y}_{1}$ only when his first-period private signal $\left(z_{1}\right)$ is $z_{1}$ Nand it is not a function of $y_{1}$ when $z_{1}=z_{1} O O ̈ z_{1} N$ On the other hand, $\underline{\mathrm{S}}^{2}$ is the set of strategies in which the agent's second-period input is a function of $\mathrm{y}_{1}$ when $z_{1}$ $=z_{1}$ Nas well as when $z_{1}=z_{1} O O ̈ z_{1} N$ 


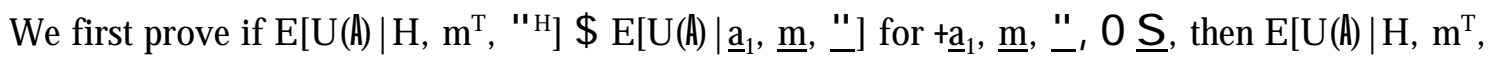
" $\left.{ }^{H}\right] \$ E\left[U\left(A \mid \underline{a}_{1}, \underline{m}, "\right]\right.$ for $\underline{\underline{t}}_{1}, \underline{m},{ }_{-}, 0 \underline{S}^{1}$ at the trial solution, i.e., constraints involving strategies in $\underline{\mathrm{S}}^{1}$ are redundant. Second, we prove if constraints involving strategies in $\underline{\mathrm{S}}^{1}$ are redundant, then constraints involving strategies in $\underline{\underline{S}}^{2}$ are also redundant.

First, suppose, without loss of generality, a representative strategy $\underline{\underline{t}}_{1}, \underline{\mathrm{m}}, \mathbf{}, \mathbf{0} \underline{\mathrm{S}}{ }^{1}$ is such that " $\left(z_{1} N y_{1} N O_{-}{ }_{-}\left(z_{1} N y_{1} \mathrm{O}\right.\right.$ for $z_{1} N$ Nequal to, say, good news (i.e., $\left.z_{1} N=G\right)$, and "_ $\left(B, y_{1} N={ }_{-}\left(B, y_{1} \mathrm{O}=\right.\right.$ " $(B, C$. E valuating the agent's expected utility of adopting this strategy, we have:

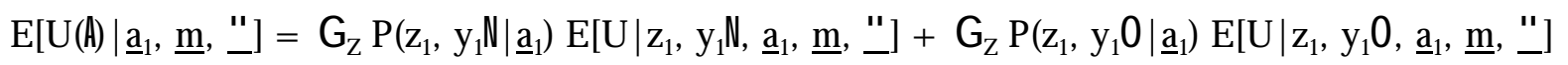

$$
\begin{aligned}
& =P\left(G, y_{1} N_{a_{1}}\right) E\left[U \mid G, y_{1} N \underline{a}_{1}, \underline{m},{ }_{-}\left(G, y_{1} N\right]\right. \\
& +P\left(B, y_{1} N \underline{a}_{1}\right) E\left[U \mid B, y_{1} N \underline{a}_{1}, \underline{m}, " \text { " }(B, G]\right. \\
& +P\left(G, y_{1} \mathrm{Q} \underline{a}_{1}\right) E\left[U \mid G, y_{1} \mathrm{Q} \underline{a}_{1}, \underline{m},{ }_{-}\left(G, y_{1} \mathrm{O}\right]\right. \\
& +P\left(B, y_{1} \mathrm{Q} \underline{a}_{1}\right) E\left[U \mid B, y_{1} \mathrm{Q} \underline{a}_{1}, \underline{m}, \underline{-}(B, G]\right.
\end{aligned}
$$

Now select a strategy, denoted $\underline{\underline{t}}_{1}^{\circ}, \underline{m}^{\circ}, \underline{-}^{\circ}$, from $\underline{\mathbf{S}}$ such that: $\underline{a}_{1}^{\circ}=\underline{a}_{1}, \underline{m}^{\circ}=\underline{m},{ }^{\prime}(G, G=$ ${ }^{\prime \prime}\left(\mathrm{G}, \mathrm{y}_{1} \mathbb{N}\right)$, and ${ }_{-}^{\circ}\left(\mathrm{B}, \mathrm{G}={ }_{-}(\mathrm{B}, \mathrm{Q}\right.$. The constraint associated with this strategy requires:

$E\left[U(\mathcal{A}) m^{\top}, "{ }^{H}\right] \$$

$$
\begin{aligned}
& E\left[U\left(A \mid \underline{a}_{1}, \underline{m}^{\circ},{ }^{\circ}\right]=P\left(G, y_{1} N \underline{a}_{1}\right) E\left[U \mid G, y_{1} N \underline{a}_{1}, \underline{m},{ }_{-}^{\circ}(G, G]\right.\right. \\
& +P\left(B, y_{1} N \underline{a}_{1}\right) E\left[U \mid B, y_{1} N \underline{a}_{1}, \underline{m}, \underline{-}^{\circ}(B, G]\right. \\
& +P\left(G, y_{1} Q \underline{a}_{1}\right) E\left[U \mid G, y_{1} Q \underline{a}_{1}, \underline{m}^{\prime \prime}{ }^{\circ}(G, G]\right. \\
& +P\left(B, y_{1} \mathrm{Q} \underline{a}_{1}\right) E\left[U \mid B, y_{1} \mathrm{Q} \underline{a}_{1}, \underline{m}, \underline{-}^{\circ}(B, G]\right.
\end{aligned}
$$

Since ${ }_{-}^{\circ}\left(G, G={ }_{-}^{\prime}\left(G, y_{1} N\right.\right.$, and ${ }_{-}^{\circ}\left(B, G={ }_{-}(B, G\right.$ by construction, the constraint can be written as: $E\left[U\left(\mathcal{A} H, m^{\top}, "{ }^{H}\right] \$\right.$

$$
\begin{aligned}
& E\left[U\left(A \mid \underline{a}_{1}^{0}, \underline{m}^{\circ}, \underline{-}^{\circ}\right]=P\left(G, y_{1} N \underline{a}_{1}\right) E\left[U \mid G, y_{1} N \underline{a}_{1}, \underline{m}, " \underline{-}\left(G, y_{1} N\right]\right.\right. \\
& +P\left(B, y_{1} N \underline{a}_{1}\right) E\left[U \mid B, y_{1} N \underline{a}_{1}, \underline{m}, \stackrel{\text { " }}{ }(B, G]\right. \\
& +P\left(G, y_{1} Q \underline{a}_{1}\right) E\left[U \mid G, y_{1} Q \underline{a}_{1}, \underline{m}, " \text { " }\left(G, y_{1} N\right]\right. \\
& +P\left(B, y_{1} Q \underline{a}_{1}\right) E\left[U \mid B, y_{1} Q \underline{a}_{1}, \underline{m}, " \text { " }(B, G]\right.
\end{aligned}
$$


Combining (AII-13) and (AII-14) yields:

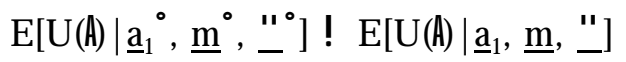

$=P\left(G, y_{1} \mathrm{O} \underline{a}_{1}\right)\left(E\left[U \mid G, y_{1} Q \underline{a}_{1}, \underline{m}, "\right.\right.$ " $\left.\left(G, y_{1} N\right]\right] ! E\left[U \mid G, y_{1} Q \underline{a}_{1}, \underline{m}, "\right.$ " $\left.\left(G, y_{1} Q\right]\right)$

Select another strategy, denoted $\underline{\underline{t}}_{1}^{\circ 0}, \underline{m}^{\circ 0},{ }^{\circ}$, from $\underline{\mathrm{S}}$ such that: $\underline{a}_{1}^{\circ 0}=\underline{a}_{1}, \underline{m}^{\circ 0}=\underline{m}, \underline{-}^{\circ \circ}(G, \sigma=$ " $\left(\mathrm{G}, \mathrm{y}_{1} \mathrm{O}\right.$, and " ${ }_{-}^{\circ \circ}\left(\mathrm{B}, \mathrm{G}={ }_{-}(\mathrm{B}, \mathrm{Q}\right.$. In similar fashion, the constraint associated with that strategy can be written as:

$$
\begin{aligned}
& E\left[U\left(\mathcal{A} H, m^{\top}, "{ }^{H}\right] \$\right.
\end{aligned}
$$

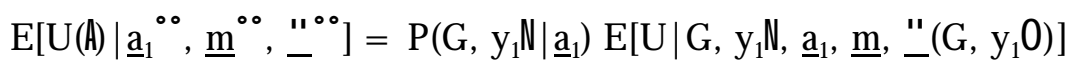

$$
\begin{aligned}
& +P\left(B, y_{1} N \underline{a}_{1}\right) E\left[U \mid B, y_{1} N \underline{a}_{1}, \underline{m}, \stackrel{\prime}{ }(B, G]\right. \\
& +P\left(G, y_{1} \mathrm{Q} \underline{a}_{1}\right) E\left[U \mid G, y_{1} Q \underline{a}_{1}, \underline{m}, \underline{-}^{\prime}\left(G, y_{1} \mathrm{O}\right]\right. \\
& +P\left(B, y_{1} Q \underline{a}_{1}\right) E\left[U \mid B, y_{1} Q \underline{a}_{1}, \underline{m}, \stackrel{-}{ }(B, G]\right.
\end{aligned}
$$

Combining (AII-13) and (AII-16) yields:

$E\left[U\left(\mathcal{A} \mid \underline{a}_{1}^{00}, \underline{m}^{\circ 0}, \underline{-}^{\circ 0}\right] ! E\left[U(A) \underline{a}_{1}, \underline{m},{ }^{\prime}\right]\right.$

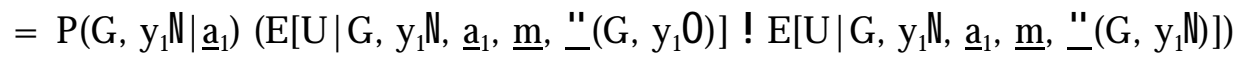

Suppose $E\left[U\left(A \mid \underline{a}_{1}, \underline{m},{ }_{-}^{\prime}\right] \# E\left[U\left(\mathcal{A} \mid \underline{a}_{1}{ }^{\circ}, \underline{m}^{\circ},{ }^{\circ}{ }^{\circ}\right]\right.\right.$, constraint (A II-13) is implied by constraint (A II-16)

and is, therefore, redundant. If $E\left[U\left(A \mid \underline{a}_{1}, \underline{m},{ }_{-}^{\prime \prime}\right]>E\left[U\left(A \mid \underline{a}_{1}{ }^{\circ}, \underline{m}^{\circ 0},{ }_{-}^{\circ 0}\right],(A \mid I-17)\right.\right.$ implies:

$E\left[U \mid G, y_{1} N \underline{a}_{1}, \underline{m}, \underline{\prime}\left(G, y_{1} N\right]>E\left[U \mid G, y_{1} \mathbb{N} \underline{a}_{1}, \underline{m}, "\right.\right.$ " $\left(G, y_{1} \mathrm{O}\right]$

But under the trial solution, $E\left[U \mid G, y_{1} N \underline{a}_{1}, \underline{m}, \underline{-}^{\prime}\left(G, y_{1} N\right]=E\left[U \mid G, y_{1} Q \underline{a_{1}}, \underline{m}, \underline{L}^{\prime}\left(G, y_{1} N\right]\right.\right.$ and $E[U \mid G$,

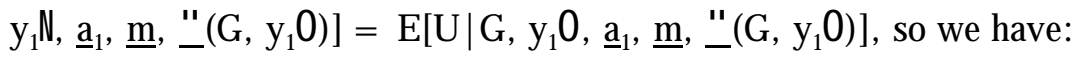

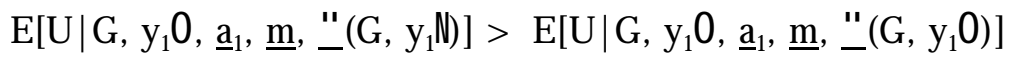

By (AII-15), this implies $E\left[U\left(\mathbb{A} \mid \underline{a}_{1}^{\circ}, \underline{m}^{\circ}, \underline{-}^{\circ}\right]>E\left[U\left(A \mid \underline{a}_{1}, \underline{m}\right.\right.\right.$, " $]$. So constraint (A II-13) is implied by constraint (AII-14) and is, again, redundant. Therefore, constraint (AII-13) is implied by either (AII-14) or (All-16) and can be eliminated under the trial solution. This is true for each strategy in the set $\underline{S}^{1}$.

A parallel argument applies to the strategies in $\underline{S}^{2}$ so that strategies in the set $\underline{S}^{2}$ can be ignored when the constraints are evaluated at the trial solution. 


\section{Proof of Proposition 3:}

Consider a numerical specification of the following:

$P\left(z_{1}=G\right)=.6, P\left(x=1 \mid z_{1}=G, H H\right)=.85, P\left(x=1 \mid z_{1}=B, H H\right)=.725$,

$P(x=1 \mid L H)=.7, P(x=1 \mid H L)=.6, P(x=1 \mid L L)=.3$,

$c(L)=0, c(H)=2,000, r=.0001$, and $\underline{U}=! \exp (! r 15,000)$.

$P\left(z_{2}=G\right)=0.5$ and $P\left(x=1 \mid z_{2}=G, H H\right)=0.82$.

Under $R_{1}, y_{1}$ is a garbling of $z_{1}$ with $P\left(y_{1}=2 \mid z_{1}=G\right)=.8$ and $P\left(y_{1}=2 \mid z_{1}=B\right)=.05$.

Under $R_{2}, y_{2}$ is a garbling of $z_{1}$ and $z_{2}$ with $P\left(y_{2}=2 \mid z_{2}=G\right)=.7, P\left(y_{2}=2 \mid z_{2}=B\right)=.3, P\left(y_{2}=2 \mid z_{1}=G\right)$ $=.73$ and $P\left(y_{2}=2 \mid z_{1}=B\right)=.5$.

W ith the specification above, the optimal contracts yielded the following expected payments.

$C\left(R_{1}\right)=21241 C\left(R_{1}, m\right)=21137 \quad C\left(R_{2}\right)=21269 C\left(R_{2}, m\right)=21113$

So at this point in the parameter space, the programs exhibit the property in proposition 3. That is, early recognition is preferred without communication (i.e., $C\left(R_{1}\right)<C\left(R_{2}\right)$ ) and late recognition is preferred with communication (i.e., $C\left(R_{2}, m\right)<C\left(R_{1}, m\right)$ ).

N ow we argue that at the neighborhood of this point in the parameter space the property is also active using implicit function theorem and a continuity argument.

Recall the expected payments, as functions defined over the parameter $P\left(y_{2}=2 \mid z_{1}=G\right)$, are implicit in the Kuhn-Tucker conditions. Strictly non-binding constraints can be ignored because there will exist an open ball around the point above that these constraints will continue to be strictly nonbinding. For the binding constraints, the Jacobian of the implicit functions is generic non-singular. Since all functions in the implicit function are continuous, the expected payment function defined by the implicit function is also continuous. Therefore there exists a parameter region with positive measures around the above point in the parameter space that the four expected payment functions will continue to possess the property in proposition 3. 